\title{
The Retinal Fate of Xenopus Cleavage Stage Progenitors Is Dependent upon Blastomere Position and Competence: Studies of Normal and Regulated Clones
}

\author{
Sen Huang and Sally A. Moody \\ Department of Anatomy and Neuroscience Program, The George Washington University Medical Center, Washington, \\ D.C. 20037
}

The clonal origin of the stage 43-44 Xenopus retina from cleavage stage precursors was quantitatively assessed with lineage tracing techniques. The retina descends from a specific subset of those blastomeres that form forebrain. The most animal dorsal midline cell (D1.1.1) produced about half of the retina, the three other dorsal ipsilateral blastomeres each produce about an eighth of the retina, and the four contralateral dorsal blastomeres and an ipsilateral ventralanimal cell together produce the remaining eighth of the retina. There was no significant spatial segregation of the clones derived from different progenitors in either the anterior-posterior or dorsal-ventral axes of the retina and no boundaries between clones were observed. Instead, the clones intermixed to form multiple radial subclones that were equivalent to those demonstrated by marking optic vesicle progenitor cells (Holt et al., 1988; Wetts and Fraser, 1988). This mosaic pattern was initiated by the beginning of gastrulation, advanced in the neural plate, and virtually complete in the optic vesicle. At optic vesicle stages cell movement within subclones was restricted, resulting in the formation of lineally related columns of cells in the mature retina.

To determine if the blastomere progenitors are determined to produce these retinal lineage patterns, the major retinal progenitor (D1.1.1) was deleted bilaterally. About $60 \%$ of the tadpoles developed normal-appearing eyes; of these the retinas in two-thirds were normal in size and the rest were smaller. The blastomeres surrounding the deleted D1.1.1 progenitors changed their contributions to retina in different ways to effect a complete or partial restoration. Ventral blastomeres, which normally contribute mainly to the tail, produced substantial amounts of the retina while dorsal blastomeres, which normally contribute mainly to the head, decreased their contribution to the retina. To determine whether these changes in retinal lineage were due to changes in blastomere position after the surgery, various other blastomeres were deleted prior to lineage mapping. Dorsal-animal blastomeres took over the retinal fate of their dorsalvegetal neighbors after those neighbors were deleted, but did not change fate after the deletion of their ventral-animal

\footnotetext{
Received Oct. 9, 1992; revised Feb. 16, 1993; accepted Mar. 1, 1993.

This work was supported by NIH Grants NS23158 and EY10096. We thank Mrs. Lianhua Yang for her excellent technical assistance.

Correspondence should be addressed to Dr. Sally A. Moody, Department of Anatomy and Neuroscience Program, The George Washington University Medical Center, 2300 I Street, N.W., Washington, D.C. 20037.

Copyright (c) 1993 Society for Neuroscience $0270-6474 / 93 / 133193-18 \$ 05.00 / 0$
}

neighbors. This result suggests that dorsal-animal blastomeres change positional values in only one direction (dorsal to vegetal) after neighbor cell deletion, and that retinal fate is dictated by blastomere position. To test this hypothesis directly, different ventral and vegetal blastomeres, which normally do not produce retina, were transplanted to the position of D1.1.1. The progeny of ventral equatorial blastomeres (V1.1.2 and V2.1.2) populated the retina in a pattern that was indistinguishable from that of normal D1.1.1, showing that position in the cleavage stage embryo is an important determinant of retinal lineage. However, progeny of transplanted ventral- or dorsal-vegetal pole blastomeres (V2.1.1 and D2.1.1) never populated the retina, demonstrating that not all blastomeres are competent to form retina.

IKey words: Xenopus laevis, retina, determination, regulation, competence, transplantation]

The mechanisms by which a multipotent embryonic cell is determined to become one particular neuronal cell type is poorly understood in vertebrates, but it is generally believed that commitment to a particular CNS phenotype occurs in a complex series of cellular decisions that affect the developmental potential of progenitor cells and the specific phenotypes of their progeny (reviewed by Jacobson, 1991; McConnell, 1991). There are several examples indicating that the developmental potential of neuronal progenitors is gradually restricted. Cell lineage in zebrafish becomes tissue specific during gastrulation, but becomes cell type specific later (Kimmel and Warga, 1986). Cortical neurons become committed to a laminar fate at the time of their final mitotic division, but are not committed to a particular cell typc until later (McConncll, 1991). In the retina, progenitors may first be restricted to produce cells in certain regions (Williams and Goldowitz, 1992) and then, perhaps as late as the terminal mitosis (Turner and Cepko, 1987; Holt et al., 1988), to produce particular cell types.

Since the retina is accessible to lineage tracing techniques during development, and is composed of a variety of easily identifiable cell types that are arranged in a highly ordered spatial pattern, it has served as a model for understanding the relationship between cell lineage and cell type determination in the nervous system. Labeling of mitotic precursor cells in the optic vesicle or perinatal retina, either by intracellular lineage dye injection (Holt et al., 1988; Wetts and Fraser, 1988; Wetts et al., 1989) or by infection with a recombinant retrovirus (Price et al., 1987; Turner and Cepko, 1987; Turner et al., 1990), elegantly demonstrates that most of the clones derived from a 
single neuroepithelial cell contain more than one retinal cell type; mitotic retinal cells rarely produce a clone consisting of a single phenotype. Although this fact has often been cited as demonstrating that cell lineage plays no role in vertebrate CNS phenotype determination, this observation addresses only one way that lineage may be important, that is, to produce a clone of cells having the same phenotype. There are several examples that show that cell lineage directs phenotype choices in other ways (reviewed in Kenyon, 1985; Stent, 1985; Davidson, 1990). Lineage patterns may direct different progenitors to produce prescribed subsets of cell types, as has been shown for nematode motoneurons (White et al., 1982). Lineage genes may direct progenitors to divide a prescribed number of times and thus control the number of cells in a population (Chalfie et al., 1981; Williams and Herrup, 1985). Finally, lineage patterns may place the descendants of a particular progenitor in prescribed domains of a tissue, such that their phenotypes are determined by regionspecific cell-cell interactions. This occurs in the nematode vulva (Sternberg and Horvitz, 1989), and has been suggested in numerous regions of the vertebrate CNS (Jacobson, 1983, 1985; Herrup, 1986; Fraser et al., 1990; Leber et al., 1990).

In order to investigate whether these other kinds of lineage patterns have a significant role in vertebrate CNS pattern formation, it is necessary to study the variation in phenotype, cell number, and spatial distribution between clones derived from the same progenitor in many different animals. Analysis of clone variation has been a most important means for establishing the role cell lineage plays in nematode development. In fact, the critical evidence that lineage has an important role in cell phenotype determination was the discovery that the mitotic history of the same identified progenitor in many different animals is invariant (Sulston et al., 1983). However, studies using techniques that mark neuroepithelial cells randomly cannot label the same progenitor repeatedly and therefore cannot demonstrate if the clone of a given progenitor is invariant in terms of cell phenotype, cell number, or regional distribution.

In this report we took advantage of the existence of stereotyped progenitor cells at the cleavage stages of frog development that can be repeatedly labeled in many different embryos. We found that in the normal embryo the retina descends from a restricted and invariant subset of those blastomeres that produce the forebrain. By quantitatively analyzing many clones derived from the same progenitor, we show that each retinal progenitor produced about the same proportion of the different retinal phenotypes. Each progenitor produced a distinct amount of retina, but the precise numbers of cells in the clones varied greatly in different embryos, demonstrating that the number of mitoses is not restricted within a lineage. We found no evidence for clonal or laminar boundaries between clones, demonstrating that blastomere origin does not restrict the spatial distribution of clones within the retina. All blastomere clones formed multiple discrete cell columns, which extended radially across retinal layers, that were equivalent to later-marked clones (Holt et al., 1988; Wetts and Fraser, 1988; Turner et al., 1990). We show that the columns descended from one blastomere were intermixed extensively with columns descended from the other blastomeres. This intermixing began during gastrulation and was virtually complete by the optic vesicle stages, at which time retinal cells begin to become postmitotic. At this latter stage, cell movement within subclones was restricted, resulting in the formation of lineally related columns of cells in the mature retina.
To test experimentally whether these progenitors are determined regarding these retinal lineage patterns, we bilaterally deleted the major progenitor of the retina and quantified the retinal contribution of the remaining blastomeres. To test whether blastomeres that normally do not produce retina are competent to do so if placed in the appropriate position, single labeled cells were either deleted from or transplanted into the site of the major retinal progenitor. The results from both approaches support the hypothesis that the position of a blastomere prior to gastrulation determines whether it will be a progenitor of the retina, in most cases regardless of the blastomere's original lineage. However, some vegetal blastomeres are not competent to make retina even when locatcd in the most "retinogenic" position.

\section{Materials and Methods}

Embryo collection. Fertilized Xenopus laevis eggs were obtained by gonadotropin-induced mating of adult frogs. After the jelly coat was chemically removed, two- and early four-cell stage embryos with the first cleavage furrow bisecting the gray crescent (Klein, 1987) were collected for later use. At 32 cells, only those embryos with stereotypic radial cleavages (type X, Jacobson 198 1a; Moody, 1987b) were used for lineage dye injection, blastomere deletion, and transplantation. By selecting this population for study we minimized any variations in furrow pattern and thus kept blastomere position consistent among animals (Moody, 1987a,b, 1989; Moody and Kline, 1990; Huang and Moody, 1992). In other words, we were able to inject, delete, and transplant progenitors that were nearly invariant among animals.

Lineage dye injection. About $1 \mathrm{nl}$ of $0.5 \%$ Texas red-dextran amine (Molecular Probes) or fluorescein-dextran amine (Molecular Probes) was pressure injected into identified blastomeres. Previous fate maps of 32-cell embryos demonstrate that the cells in the retina are derived mainly from five animal pole blastomeres on each side of the animal (Dale and Slack, 1987a; Moody, 1987b). According to Jacobson's nomenclature these five blastomeres are D1.1.1, D1.1.2, D1.2.1, D1.2.2, and V1.2.1 (Fig. 1A; Jacobson and Hirose, 1981). According to Nakamura's nomenclature these blastomeres are $\mathrm{A} 1, \mathrm{~B} 1, \mathrm{~A} 2, \mathrm{~B} 2$, and $\mathrm{A} 3$, respectively (Nakamura et al., 1978). For our quantitative maps, surrounding neighbors also were injected in order that no potential or minor progenitor be missed.

Tissue processing. The embryos were fixed by immersion in $0.1 \mathrm{M}$ phosphate-buffered saline (PBS) containing 4\% paraformaldehyde and $3 \%$ sucrose al stages $10-25$ and $43-44$ (Nieuwkoop and Faber, 1964) and were cut at $14 \mu \mathrm{m}$ in transverse or sagittal serial sections with a cryostat. Sections were collected on slides, washed in $0.1 \mathrm{M}$ PBS, and coverslipped in $95 \%$ glycerol.

Quantitative analysis of clones in the retina. The data for the quantitative analyses were collected from the retina at stages $43-44$, when the neurogenesis of the retina is almost completed and the retinal layers and the cell types are easily identified (Holt et al., 1988). The retina was divided into anterior, middle, or posterior thirds, and dorsal, central, or ventral thirds with reference to the position of the lens. The number of fluorescently labeled cells in each third was counted from every other tissue section, and accordingly the total clonal ccll numbers and distribution to retinal layers were calculated. In addition, these sections were photographed and the area of the retina on the prints was measured with the Bioquant System IV image analysis program. Based on these measurements the total volume of the retina and the cell density of labeled clones derived from each blastomere were calculated. Only embryos in which individual cells were discernable were included in the cell counts; at least five embryos were counted for each blastomere per manipulation.

Blastomere ablation and transplantation. The detailed procedures of blastomere deletion and transplantation have been described in previous reports (Gallagher et a1., 1991; Huang and Moody, 1992). In this part of the study three groups of lineage dye injection and experimental operations were performed to test blastomere determination and competence regarding retinal ccll lincagc. First, to test whether a normal retina can develop when an embryo does not contain its full complement of retinal progenitors, both D1.1.1 blastomeres were removed from the embryo with sharpened forceps (Fig. 1C,D). Care was taken so that no cellular debris remained in the wound, which could affect the regulative 

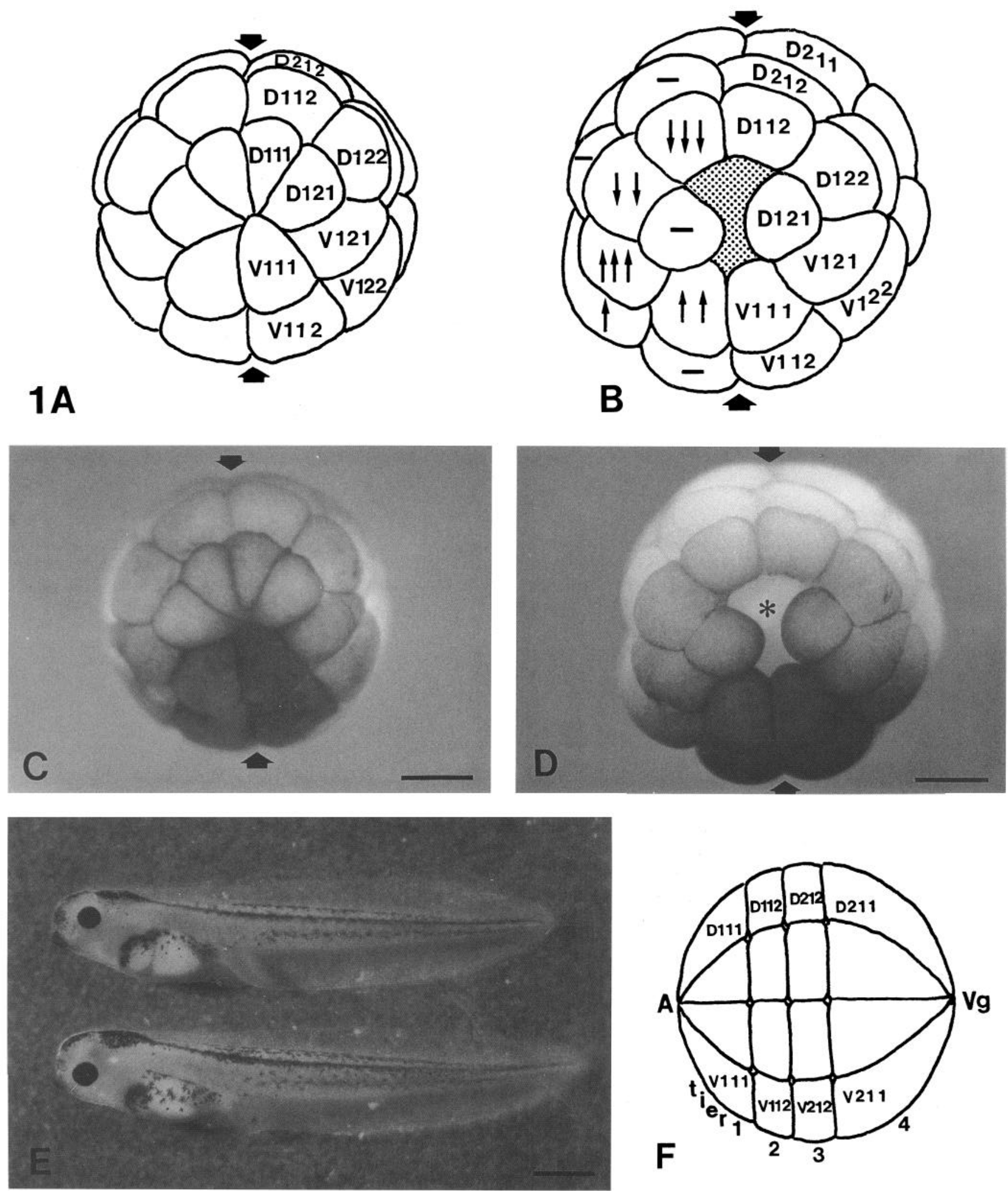

Figure 1. $A-D$, Diagrams and photographs of a 32-cell embryo (animal pole view) before $(A, C)$ and immediately after $(B, D)$ D1.1.1 deletion. The nomenclature of the blastomeres is after Jacobson and Hirose (1981). The thick arrows point to the midsagittal cleavage. The thin arrows in $B$ indicate the relative changes in retinal lineage for each blastomere after deletion of both D1.1.1 (indicated by dotted patch in $B$ and an asterisk in $D$ ). The dash in some blastomeres in $B$ indicates no change in retinal lineage (see also Fig. 5). Scale bars, $500 \mu \mathrm{m}$. $E$, Two examples of stage 43 embryos with normal-appearing eyes in which both D1.1.1 were deleted. Scale bar, $1000 \mu \mathrm{m}$. $F$, Lateral view of a 32-cell embryo showing the blastomere tiers and all the vegetal cells used in the transplantation studies. $A$, animal pole; $V g$, vegetal pole. The dorsal side is to the top and the ventral side is to the bottom. 
Table 1. The number of retinal cells that descend from each blastomere of 32-cell embryos

\begin{tabular}{lcclcr} 
Blastomere & $\begin{array}{l}\text { Cell number } \\
\text { (mean } \pm \text { SEM) }\end{array}$ & \% Total & Range & $\begin{array}{l}\text { Cell } \\
\text { density } \\
\text { (cells/mm } / \text { m }^{2}\end{array}$ & $\begin{array}{l}\text { \% } \\
\text { Total }\end{array}$ \\
\hline D1.1.1 ipsi $^{\alpha}$ & $4774 \pm 600$ & 49.7 & $3620-7054$ & $7194 \pm 2239$ & 43.7 \\
D.1.1.1 contra & $668 \pm 348$ & 7.0 & $196-2028$ & $1411 \pm 741$ & 8.6 \\
D1.1.2 ipsi & $1338 \pm 402$ & 13.9 & $258-2748$ & $2006 \pm 1102$ & 12.2 \\
D1.1.2 contra & $442 \pm 176$ & 4.6 & $10-1034$ & $1096 \pm 380$ & 6.7 \\
D1.2.1 ipsi & $1136 \pm 362$ & 11.8 & $242-1957$ & $2336 \pm 1099$ & 14.2 \\
D1.2.1 contra & $36 \pm 30$ & 0.4 & $0-155$ & $137 \pm 119$ & 0.8 \\
D1.2.2 ipsi & $1116 \pm 432$ & 11.6 & $384-2699$ & $2140 \pm 1328$ & 13.0 \\
D1.2.2 contra & $34 \pm 20$ & 0.4 & $0-92$ & $61 \pm 39$ & 0.4 \\
V1.2.1 ipsi & $62 \pm 8$ & 0.6 & $42-90$ & $71 \pm 48$ & 0.4 \\
V1.2.1 contra & 0 & & & &
\end{tabular}

${ }^{a}$ Ipsilateral.

${ }^{b}$ Contralateral.

abilities of the remaining cells (Roux, 1888). To demonstrate which of the remaining blastomeres regulate their lineages, one or two blastomeres in one embryo were injected with $1 \mathrm{nl}$ of lineage dye, and then both D1.1.1 blastomeres were removed. As a control, only the vitelline membrane was removed from embryos after lineage dye injection.

In a second set of experiments, several combinations of dye injection and cell deletions were performed to determine whether positional changes of the remaining blastomeres account for the changes in retinal lineages observed in the first experiment. (1) Deletion of both V1.1.1 blastomeres was combined with D1.1.1 injection to see if D1.1.1 descendants move ventrally to adopt the V1.1.1 fate and contribute less to the retina. (2) Unilateral deletion of D1.1.2 was combined with DI.1.1 injection to see if D1.1.1 descendants move dorsal-vegetally to adopt the D1.1.2 fate and contribute less to the retina. (3) Unilateral deletion of D2.1.2 was combined with D1.1.2 injection to see if the descendants move into the vegetal hemisphere to adopt the D2.1.2 fate and no longer produce retinal cells.

To test directly whether blastomere position determines retinal fate, the midline cells that normally do not contribute to the rostral CNS or retina (V1.1.2, V2.1.2, V2.1.1, D2.1.2, and D2.1.1; Fig. $1 F$ ) were labeled with lineage dye and then transplanted into the position of D1.1.1 in an unlabeled host. Single donor blastomeres were transplanted into the space of bilaterally removed D1.1.1 to accommodate the bigger donor cells. In addition, labeled D1.1.1 was transplanted into the V1.1.2 position to test whether it continues to produce retina in a novel position. As a control, labeled D1.1.1 was orthotopically transplanted. Only embryos with normal retinal structure were collected for the quantitative analyses.

\section{Results}

\section{Blastomere progenitors contribute different amounts of the} retina

The present study confirms the findings of previous fate maps (Dale and Slack, 1987a; Moody, 1987b) that five animal hemisphere blastomeres (D1.1.1, D1.1.2, D1.2.1, D1.2.2, V1.2.1; Fig. $1 A$, Table 1 ) on each side of the 32-cell embryo give rise to the retina. This is a restricted subset of those blastomeres that normally contribute to the forebrain (Huang and Moody, 1992). By precisely quantifying each blastomere's contribution to the retina, we show that no other blastomere has any progeny in the retina. Each of the five retina-producing blastomeres contributes a much larger number of ipsilateral than contralateral cells, and each contributes different numbers of cells to the retina (Fig. $2 A$, Table 1). On the average, each retina descends $50 \%$ from ipsilateral D1.1.1, 14\% from ipsilateral D1.1.2, 12\% from ipsilateral D1.2.1, 12\% from ipsilateral D1.2.2, 7\% from contralateral D1.1.1, 5\% from contralateral D1.1.2, and $<1 \%$ each from ipsilateral V1.2.1, contralateral D1.2.1, and contralateral D1.2.2. These differences also are observed if the cell numbers from the different blastomeres are converted to retinal cell density (cells $/ \mathrm{mm}^{2}$; Table 1 ), which eliminates any variation due to differences in the number of cells generated at the different embryonic stages (43 vs 44 ).

As described previously for other cell types (Moody, 1987a,b, 1989; Huang and Moody, 1992), each blastomere usually produces a consistent clonal pattern among embryos, but this pattern is not invariant. That is, the number and location of the labeled cells may vary from embryo to embryo after injection of the same blastomere progenitor. For example, after D1.1.1 injection labeled cells always were in both retinas, but the size of the ipsilateral clone in one embryo could be twice as large as that in another embryo (Table 1). Furthermore, the number of cells in each clone from a particular blastomere varied from one embryo to another. The range in cell number was only about twofold for ipsilateral D1.1.1 and V1.1.2, but was about 10fold for the other blastomeres (Table 1). Therefore, retinal progenitors are not determined to produce a set number of cells; that is, the different retinal lineages are not each characterized by an invariant number of mitoses.

\section{There are no clonal boundaries in the retina}

In order to discern whether ancestry restricts the spatial distribution of clones, the cell density of different clones in six retinal thirds (anterior, middle, posterior, dorsal, central, ventral) was measured. The descendants from each blastomere were neither evenly distributed throughout the retina, nor restricted to a particular sector of the retina (Figs. 3-5). Rather, they often were distributed in a shallow gradient across the retina. In the ipsilateral retina, D1.2.1, D1.2.2, and V1.2.1 contributed more to the anterior (nasal) third, while D1.1.1 and D1.1.2 contributed slightly more to the posterior (temporal) third of the retina (Fig. 3A). The clone derived from D1.2.1 showed the largest regional gradient: this blastomere contributed 10 times more to anterior than to posterior retina ( $p<0.05, t$ test). In the contralateral retina, no anterior-to-posterior gradients were discerned. In the ipsilateral retina, most of the clones were evenly distributed in the dorsal-ventral direction, although D1.2.2 had slightly fewer cells on the ventral side (Fig. $4 A$ ). In the contralateral retina the clones derived from D1.1.1 and D1.1.2 were 


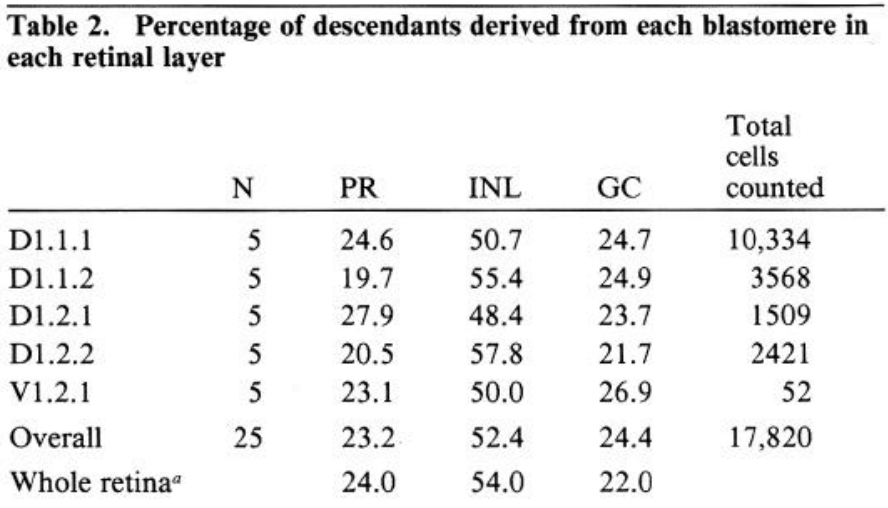

The data were gathered from the middle third of the retina where the cross section of the tissue illustrates the retinal layers most clearly. The data are expressed as the means from five embryos per blastomere. With a $\chi^{2}$ analysis, there is no difference in distribution between the blastomeres $(p>0.25)$.

${ }^{a}$ Data from Holt et al. (1988).

distributed more in the ventral third. Although there were some shallow gradients of clone distribution along the retinal axes, descendants of particular blastomeres were not restricted to particular regions of the retina; all regions of the retina were of polyclonal descent (Fig. 5).

\section{There is no preferred clonal laminar distribution}

Previous studies in Xenopus demonstrated that the majority of clones derived from optic vesicle progenitor cells span two or three retinal layers (Holt et al., 1988; Wetts and Fraser, 1988; Wetts et al., 1989), and thus are not restricted by lineage to a particular cellular lamina. However, since mammalian visual cortical cells are restricted to whichever lamina they will populate before their phenotype is restricted (McConnell, 1991), it seemed possible that the different retinal lineages could have preferred, if not restricted, laminar destinations. By counting the number of cells in each retinal cell layer derived from each blastomere in a large number of animals, we observed no difference among the blastomeres (Table 2). For all blastomeres, inner nuclear layer (INL) cells account for approximately half of the descendants of each blastomere and photoreceptors (PR) and ganglion cells (GC) each account for one-fourth. These figures are close to the overall proportion of the different cells in the whole Xenopus retina (Holt et al., 1988). This result demonstrates that each blastomere clone is representative of the entire retina, in terms of cellular phenotypes, and that none of the blastomeres place descendants in a preferred lamina. However, as discussed below, the laminar distribution of cells within some radial subclones from different blastomeres is different from that of the whole retina.

\section{The retina is a mosaic of radial subclones}

The descendants of each blastomere in the stage 43-44 retina did not form a coherent mass separated from the descendants of other blastomeres by clonal boundaries. Instead, they were dispersed in many discrete clusters that were intermixed with similar clusters descended from other blastomeres (Fig. 5). Each cluster was composed of radial columns that spanned all retinal layers and were very similar in appearance to the larger clones initiated in the optic vesicle by either retroviral infection (Turner and Cepko, 1987; Turner et al., 1990) or intracellular injection (Holt et al., 1988; Wetts and Fraser, 1988; Wetts et al., 1989). Each cell cluster, although having discrete boundaries, was not
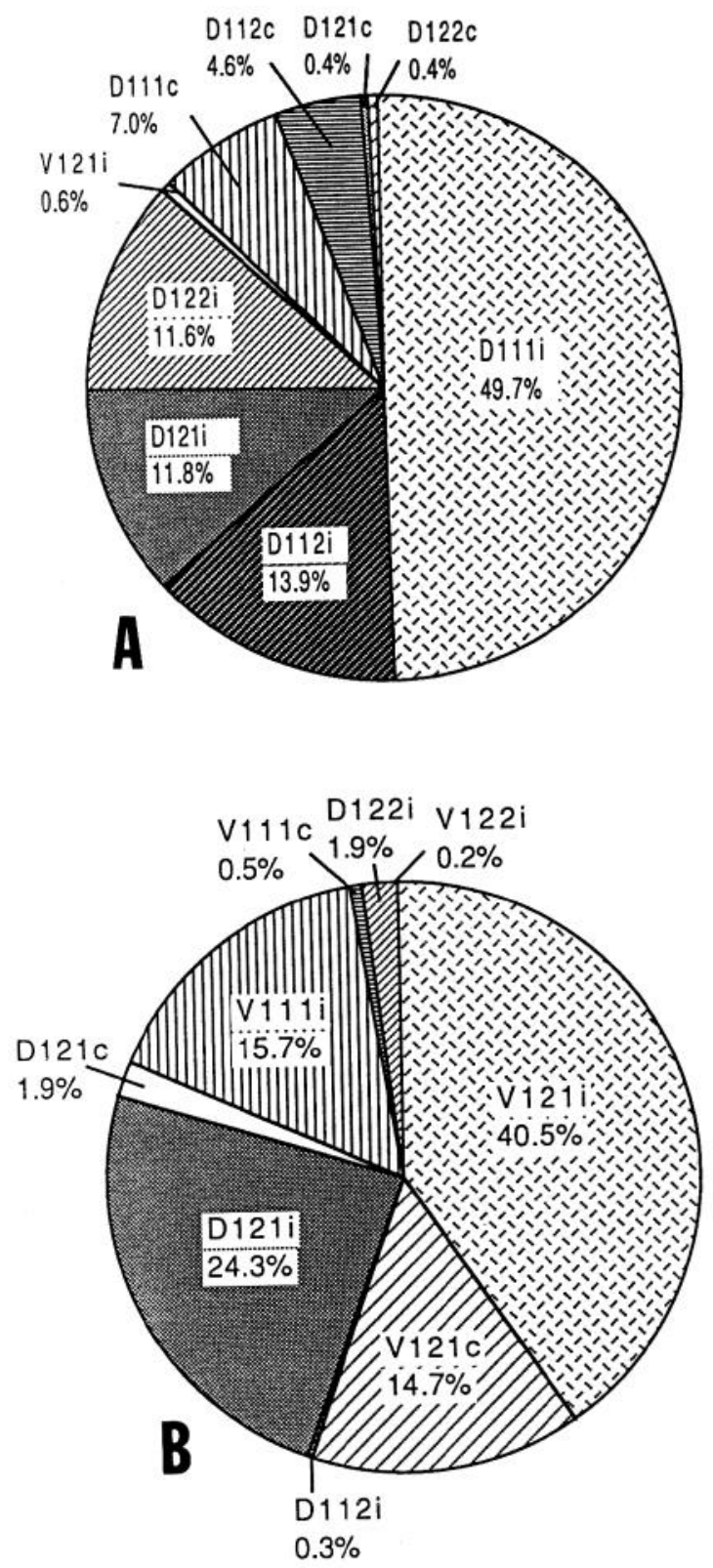

Figure 2. A, A pie graph showing the ipsilateral $(i)$ and contralateral (c) contributions to the normal retina from each blastomere. Ipsilateral D1.1.1 is the major contributor, producing about half of the retina; the other three dorsal blastomeres each produce about one-eighth of the retina, and the remaining one-eighth descends from contralateral dorsal blastomeres and one ventral blastomere (V1.2.1i). B, A pie graph showing the clonal composition of the retina in embryos from which both D1.1.1 cells were deleted. Together the V1.2.1 blastomeres become the major contributors, producing more than half of the retina; this approximates the normal contribution of both D1.1.1 (compare to $A$ ). Blastomeres D1.2.1 and V1.1.1 produce most of the rest of the retina.

a solid cell mass, as is the case for clonal cohorts in the retina of chimeric mice (Williams and Goldowitz, 1992) and mice marked with retrovirus at early embryonic days (Turner et al., 1990). Instead, the Xenopus cell cluster was dominated by labeled cells, but also contained unlabeled cells derived from other blastomeres in any of the retinal layers (Fig. 5; see also Wetts et al., 1989). In addition, a few labeled cells lay between labeled clusters (Fig. $5 D$ ), and their cluster membership could not be ascertained. As proposed in the mouse (Williams and Goldow- 

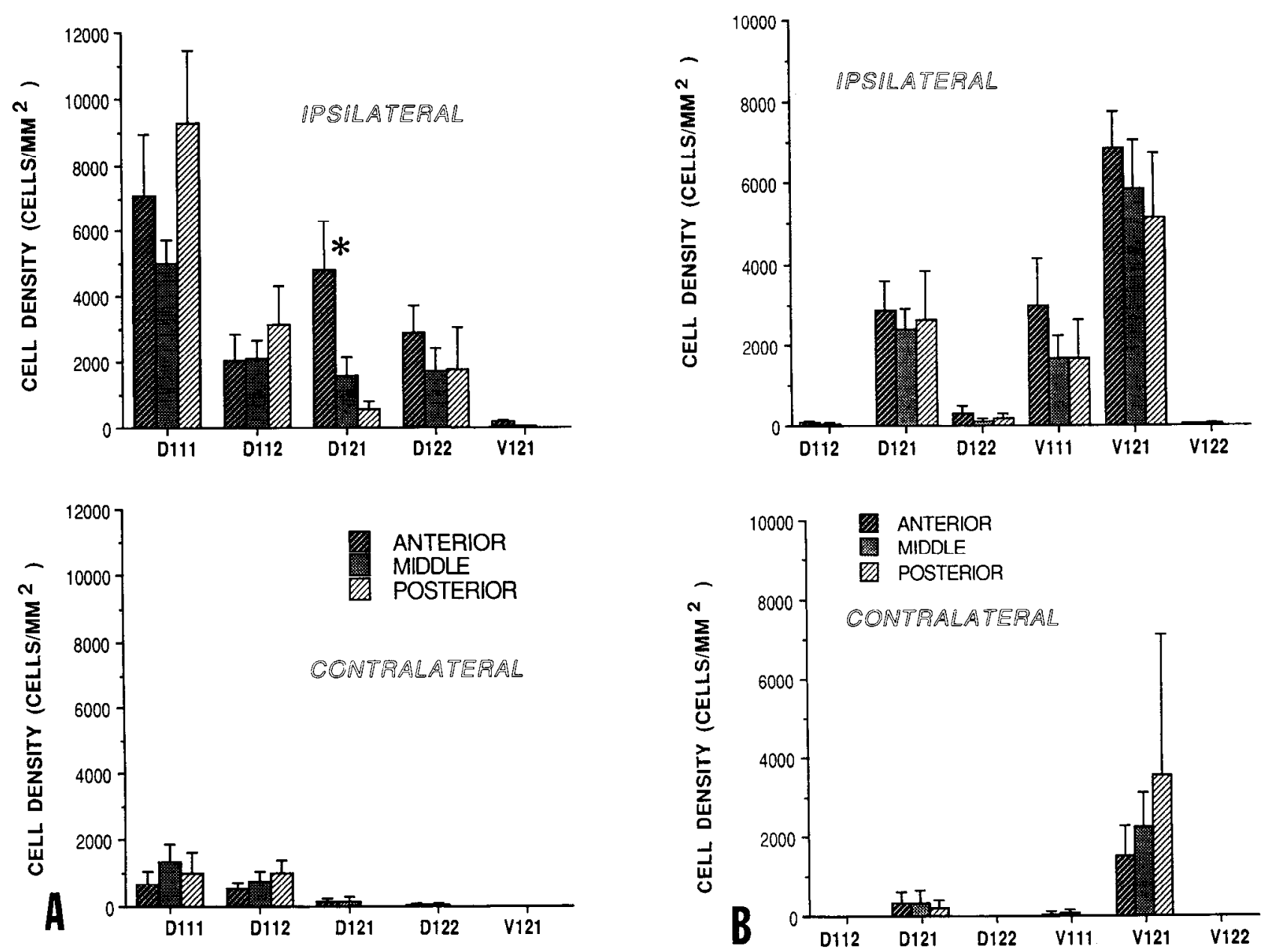

Figure 3. A, The blastomeres' regional contributions to anterior, middle, and posterior thirds of the normal retina are presented in terms of cell density. Ipsilaterally, D1.1.1 and D1.1.2 contribute more posteriorly, while D1.2.1, D1.2.2, and V1.2.1 contribute more anteriorly. However, the only significant regional difference in cell density was observed in the D1.2.1 clone $\left(^{*}, p<0.05, t\right.$ test). No contralateral differences were observed. $B$, The regional contribution of each remaining blastomere to anterior, middle, and posterior thirds of the retina in D1.1.1-deleted embryos. Ipsilaterally, V1.1.1 and V1.2.1 contribute slightly more to the anterior retina, and contralaterally, V1.2.1 contributes slightly more to posterior retina. No regional differences were observed for the other blastomeres.

itz, 1992), we suggest that these clusters represent radial units or subclones that descend from separate neuroepithelial precursors.

When a blastomere produced many subclones in the retina, the boundaries between subclones were not distinct (e.g., as seen after D1.1.1 injection; Fig. $5 D$ ), but in some cases there were only one or a few subclones in the entire retina (e.g., Fig. $5 A-$ $C)$. In these cases the cell number and cell type composition of the radial subclones were quantified (Table 3 ). In contrast to radial cells marked late in development (Holt et al., 1988; Wetts and Fraser, 1988), almost every subclone contained every retinal cell type. Rather than identifying each cell in a clone by morphology, we categorized retinal cells according to the layers in which they resided, using the criteria of Holt et al. (1988). In the INL, cells were subdivided as belonging to onc of threc sublayers: cells on the vitreal side $\left(I_{1}\right)$ are mainly amacrine with a few interplexiform cells, cells in the middle $\left(\mathrm{I}_{2}\right)$ are mainly bipolar and Müller cells, and cells on the epithelial side $\left(\mathrm{I}_{3}\right)$ are mainly horizontal and bipolar cells. In 13 out of 16 cases the radial subclone contained cells in all five retinal sublayers. As exceptions, two D1.1.2 subclones did not contain GCs and one
V1.2.1 subclone did not contain PRs. Thus, the radial subclones in our material most likely represent the progeny of a single neuroepithelial cell that produces all retinal cell types. It should be noted that these subclones are all different in size, demonstrating (as in Table 1) that the number of mitoses in subclones is not invariant.

Interestingly, although the proportion of cells in the different laminae in the entire retinal clone of every blastomere was quite similar to that of the whole retina (see previous section and Table 2), there was considerable variation from this pattern within individual radial subclones (Table 3 ). For example, the three D1.1.2 subclones contained a large proportion (82\%) of cells in the INL and a very small proportion (2\%) in the GC layer. The D1.2.2 and V1.2.1 subclones contained slightly more cells in the INL and slightly fewer PRs than the whole retina. The boundaries between subclones from D1.1.1 rarely were sufficiently distinct to analyze, and thus only one is presented (Table 3); that particular clone contained the highest proportion of PRs. These results indicate that several of the radial subclones show preferred laminar distributions, which loosely correlated with blastomere of origin. 

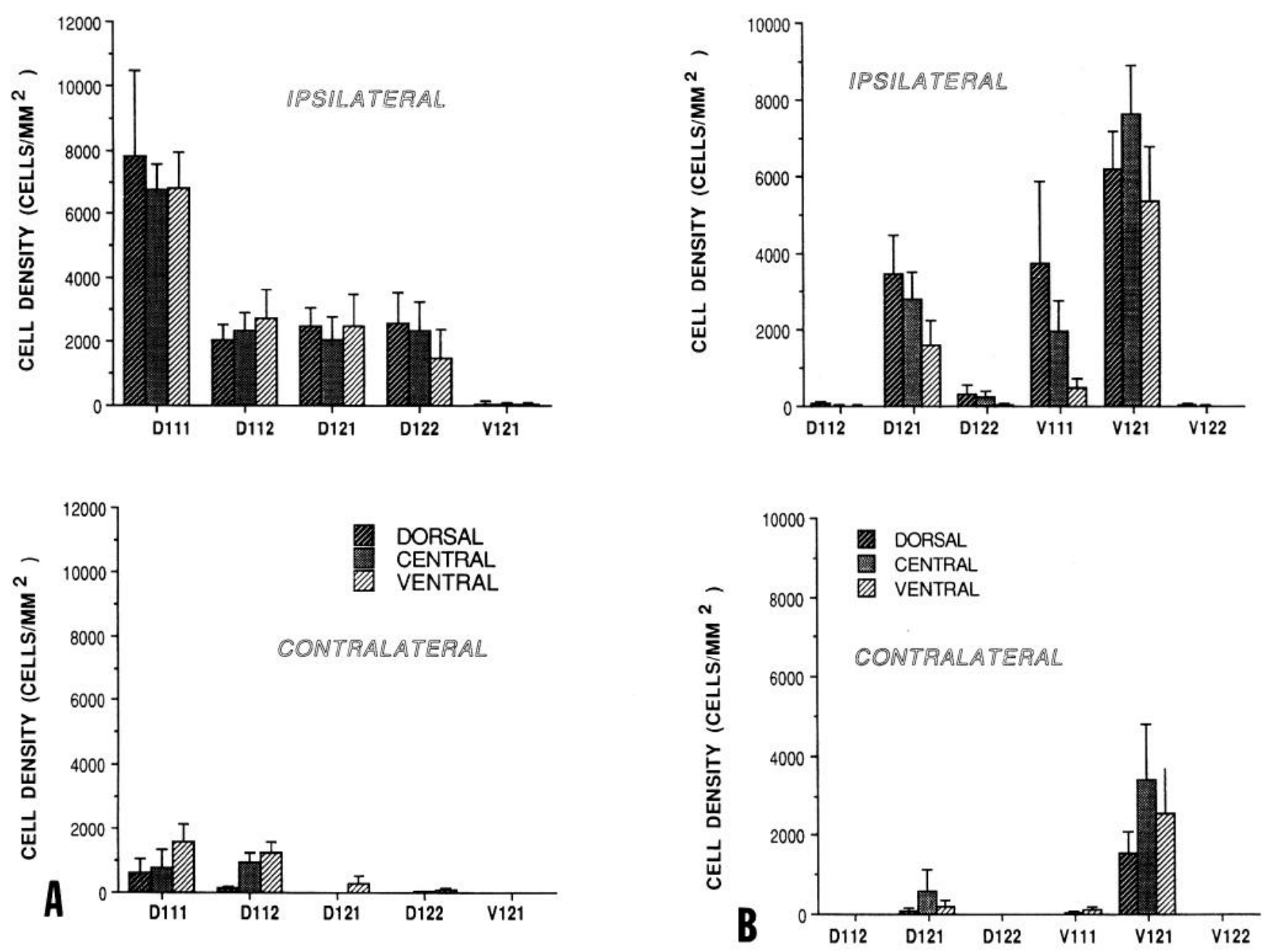

Figure 4. A, The blastomeres' regional contributions to dorsal, central, and ventral thirds of the normal retina are presented in terms of cell density. No obvious distribution gradients were observed on the ipsilateral side, but on the contralateral side dorsal blastomeres contribute more to the ventral retina. $B$, The regional contribution of each remaining blastomere to dorsal, central, and ventral thirds of the retina in D1.1.1-deleted embryos. D1.2.1 and V1.1.1 contribute slightly more to the ipsilateral dorsal retina. V1.2.1 contributes slightly more to central retina, both ipsilateral and contralateral.

\section{Early mixing of blastomere clones}

Since the subclones from the blastomere progenitors are intermixed as radial clusters in the stage $43-44$ retina, and since the clones initiated from the optic vesicle neuroepithelial cells are restricted to radial clusters (Holt et al., 1988; Wetts and Fraser, 1988), a restriction in cell mixing seems to occur prior to the final mitosis. We examined the pattern of the clones derived from the different blastomere progenitors during optic vesicle formation, neurulation, and gastrulation in order to determine when clonal mixing starts, when it ceases, and when the radial subclones are established.

The basic pattern of blastomere clones in the stage 25 optic vesicle, at which time retinal cells begin to be born (Holt et al., 1988), closely resembled that of the stage 43-44 retina, at which time nearly the entire complement of embryonic retinal cells are postmitotic (Holt et al., 1988). That is, the labeled cells derived from one blastomere were dispersed throughout the entire optic vesicle and were intermixed with cells derived from other blastomeres (Fig. 6). The density of the radial subclones was similar to that observed in the stage 43-44 retina (compare Figs. 5, 6). Thus, at the time when previous studies initiated clones from Xenopus optic vesicle cells (Holt et al., 1988; Wetts and Fraser, 1988), the blastomere clones already have formed a lineage mosaic. The radial subclones in the optic vesicle consisted of either (1) one single, columnar, neuroepithelial cell that spans the vesicle; (2) small groups of two or three such cells; or (3) small clusters of cells composed of columnar neuroepithelial cells and cells that have withdrawn a process from either the epithelial or vitreal surface (Fig. 6). These latter cells appeared to be postmitotic and were observed only in the larger clusters. It is significant that at the time when retinal cells begin to leave the mitotic cycle, subclones derived from neuroepithelial precursors remained coherent; there is little lateral migration of cells within the mitosing population.

Examination of earlier stages also revealed considerable mixing between different lineages in the prospective retinal areas. In the neural plate (stage 14) the retinal field is located at the most rostral part of the plate and includes the adjacent neural crest (Brun, 1981; Eagleson and Harris, 1990). The labeled columnar cells in the retinal field were well separated from one another by the progeny of other blastomeres (Fig. $7 A$ ). The proportion of cells from the different blastomeres was similar to their final contribution to the differentiated retina. For ex- 

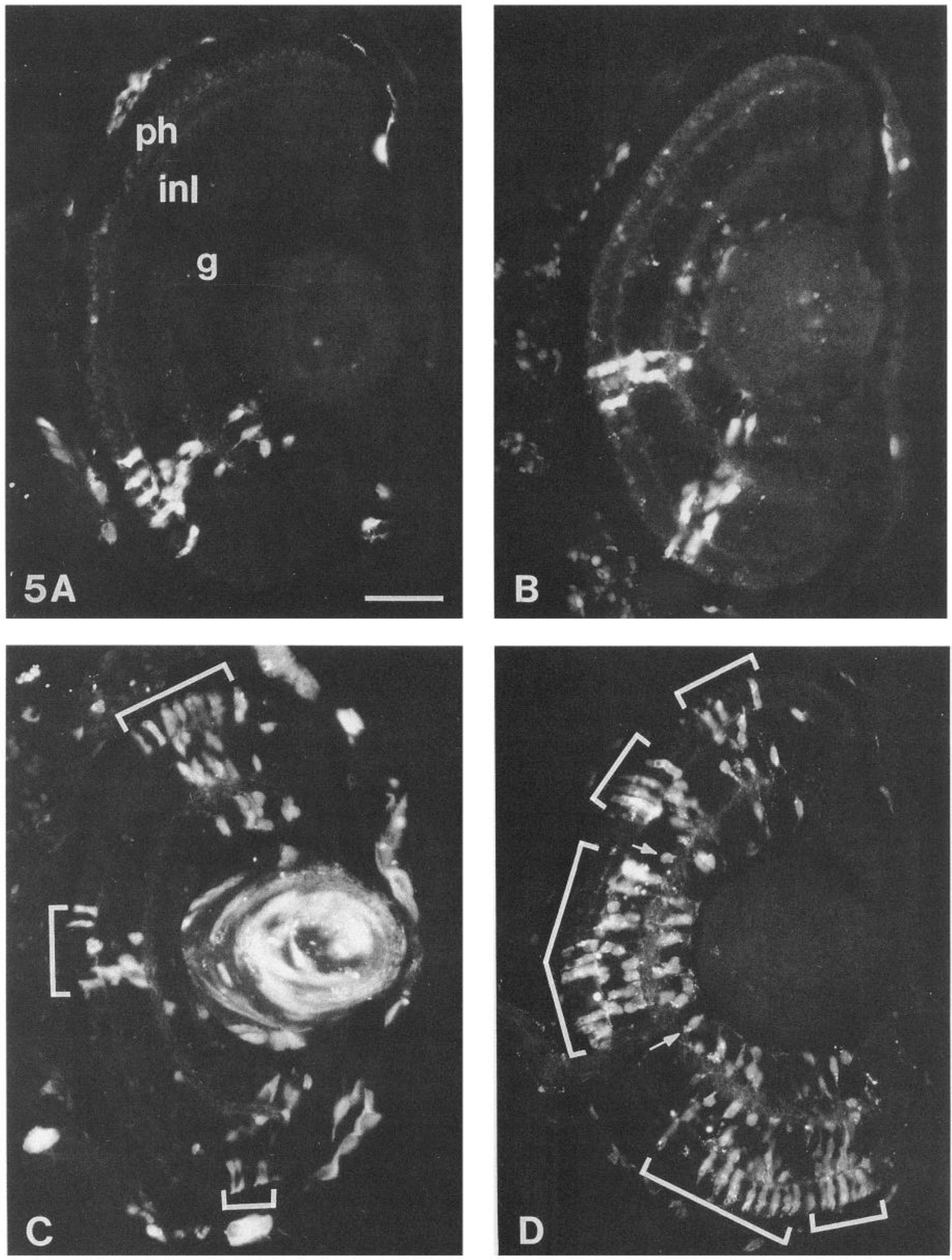

Figure 5. Photomicrographs of radial subclones in the stage $43-44$ retina. $p h$, photoreceptor layer; inl, inner nuclear layer; $g$, ganglion layer. $A$, One radial subclone derived from contralateral D1.1.1 contains cells in all retinal layers. Within the cell cluster, there are some unlabeled profiles, indicating that cell mixing between lineages has occurred. $B$, Two small radial subclones derived from ipsilateral D1.2.2 each contain cell types in all retinal layers. These subclones form coherent columns. $C$, Three radial subclones (brackets) derived from ipsilateral D1.2.1 are dispersed far apart in different retinal sectors. All retinal cell types are contained in the subclone in the dorsal sector (top). D, After ipsilateral D1.1.1 injection many labeled descendants are distributed throughout the retina. The segregation of cell clusters into radial subclones is not as clear as in other cases (compare $A-C$ ) and a few cells (arrows) lay between the labeled clusters. However, five columnar groups can be recognized (brackets). Scale bar, $50 \mu \mathrm{m}$. 
Table 3. Percentage of cells in each retinal layer derived from different radial subclones

\begin{tabular}{|c|c|c|c|c|c|c|c|}
\hline Blastomere & $\begin{array}{l}\text { Total } \\
\text { number }\end{array}$ & $\mathrm{PR}^{a}$ & $\mathbf{I}^{b}$ & $\mathbf{I}_{2}^{c}$ & $\mathrm{I}_{1}{ }^{d}$ & $\begin{array}{l}\text { Total } \\
\text { I }\end{array}$ & $\mathrm{GC}^{e}$ \\
\hline D1.1.1 contra & 136 & 36.0 & 19.1 & 13.2 & 13.2 & $(45.6)$ & 18.4 \\
\hline D1.1.2 ipsi $^{g}$ & 42 & 9.5 & 11.9 & 28.6 & 43.9 & (84.4) & 7.1 \\
\hline D1.1.2 ipsi & 8 & 12.5 & 50.0 & 0 & 37.5 & $(87.5)$ & 0 \\
\hline D1.1.2 contra & 8 & 25.0 & 12.5 & 37.5 & 25.0 & $(75.0)$ & 0 \\
\hline D1.2.1 contra & 71 & 28.2 & 5.6 & 23.9 & 26.8 & $(56.3)$ & 15.5 \\
\hline D1.2.1 contra & 148 & 23.6 & 18.9 & 18.9 & 22.4 & $(60.2)$ & 16.2 \\
\hline D1.2.1 contra & 32 & 28.1 & 9.4 & 34.4 & 6.3 & $(50.1)$ & 21.8 \\
\hline D1.2.2 contra & 36 & 19.5 & 13.9 & 33.3 & 25.0 & $(72.2)$ & 8.3 \\
\hline D1.2.2 contra & 30 & 16.7 & 10.0 & 23.3 & 26.6 & $(59.9)$ & 23.4 \\
\hline D1.2.2 ipsi & 17 & 41.2 & 11.8 & 23.5 & 17.6 & $(52.9)$ & 5.9 \\
\hline D1.2.2 ipsi & 10 & 10.0 & 10.0 & 20.0 & 30.0 & $(60.0)$ & 30.0 \\
\hline V1.2.1 ipsi & 47 & 27.6 & 8.5 & 25.6 & 25.5 & $(59.6)$ & 12.8 \\
\hline V1.2.1 ipsi & 26 & 23.1 & 19.2 & 23.1 & 26.9 & $(69.2)$ & 7.7 \\
\hline V1.2.1 ipsi & 12 & 16.7 & 25.0 & 16.7 & 33.3 & $(75.0)$ & 8.3 \\
\hline V1.2.1 ipsi & 11 & 0 & 18.2 & 36.3 & 27.3 & $(81.8)$ & 18.2 \\
\hline V1.2.1 ipsi & 104 & 31.7 & 14.5 & 19.2 & 15.4 & $(49.1)$ & 19.2 \\
\hline Mean & & 26.3 & 15.0 & 21.4 & 21.7 & & 15.6 \\
\hline
\end{tabular}

\footnotetext{
${ }^{a}$ Photoreceptors.

${ }^{b}$ Inner nuclear layer 3, consisting of mainly horizontal and bipolar cells.

c Inner nuclear layer 2, consisting of mainly bipolar and Müller cells.

${ }^{d}$ Inner nuclear layer 1 , consisting of mainly amacrine and interplexiform cells.

- Ganglion cells.

Contra $=$ clone from contralateral side.

${ }^{g}$ Ipsi $=$ clone from ipsilateral side.
}

ample, many labeled cells in the retinal field were from D1.1.1 and very few were from V1.2.1 (Fig. $7 B$ ). In the gastrula the retinal area lies in the prospective anterior neural area (Keller, 1975). The columnar cells derived from the different retinal blastomere progenitors in this region as early as stage 10 formed a mosaic with the descendants from other blastomeres (Fig. 8). However, the mixing was less extensive than at neural plate stages, suggesting that mixing begins only shortly before the onset of gastrulation. These results indicate that the prospective retinal field becomes a lineage mosaic well before neural induction takes place.

\section{The retina can be restored after its major progenitor is deleted}

D1.1.1 produces over $50 \%$ of the cells in the retina. After deletion of both D1.1.1,60\% of the embryos developed normally (Table 4) and had normal-appearing eyes (e.g., Fig. 1E). The retinal layers were well organized and all of the retinal cell types could be identified (Fig. 9). However, these restored retinas were not all the same size as those of normal embryos (Fig. 10). Of the embryos that were not externally normal $(40 \%)$, half had eye defects (Table 4 ), which included no eyes $(0.5 \%)$, only one eye $(7.0 \%)$, much smaller eyes $(7.0 \%)$, or histologically distorted eyes $(4.7 \%)$, and half had body defects, which included an open dorsal axis $(7.0 \%)$ or failure to gastrulate $(13.9 \%)$. In the control group, in which only the vitelline membrane was removed, $4.7 \%$ of the embryos had eye defects and 9.3\% had body defects (Table 4 ), indicating that the operational procedure caused nonspecific damage. However, eye defects occurred in the deletion cases $15 \%$ more frequently than in the controls, indicating that the removal of the two major retinal progenitors can prohibit full retinal development.
In summary, although in the majority of cases the remaining blastomeres regulate to produce a normal appearing eye, often they do not completely compensate for the removal of the major retinal progenitors.

\section{Remaining blastomeres respond differently to the bilateral deletion of D1.1.1}

To define which of the remaining blastomeres regulated to restore the retinal lineages, we injected the different blastomeres with lineage dyes before the removal of both D1.1.1 and then quantified their clonal contribution to the retina. None of the tier 3 blastomeres (Fig. $1 F$ ) nor the tier 2 ventral midline blastomere (V1.1.2) gave rise to retina (Fig. $1 B$ ). However, almost all other animal blastomeres changed fate, some by increasing their contribution to retina and some by decreasing their contribution to retina (Fig. $1 B$ ). Ipsilateral D1.2.1 (ipsilateral with respect to the retina analyzed) remained one of the major contributors, but most of the retina now descended from ventral cells (Fig. $2 B$ ). V1.2.1 became the major retinal progenitor, producing $40 \%$ of ipsilateral and $15 \%$ of contralateral retina. This approximates the normal contribution of the deleted D1.1.1. Ipsilateral V1.1.1, which normally does not contribute to retina, produced retinal cells in 12 of 13 cases and became one of the largest contributors. As compared to normal cell counts, ipsilateral V1.1.1 and V1.2.1 and contralateral V1.2.1 significantly increased their contributions to retina, whereas ipsilateral D1.1.2 and D1.2.2 significantly decreased their contributions (Fig. 11). Blastomere V1.2.2, which never contributes to retina in normal embryos, gave rise to a small number of retinal cells in two of 13 cases. As shown for the normal retina (Table 1), the contribution to the retina of the same blastomere after deletion of 


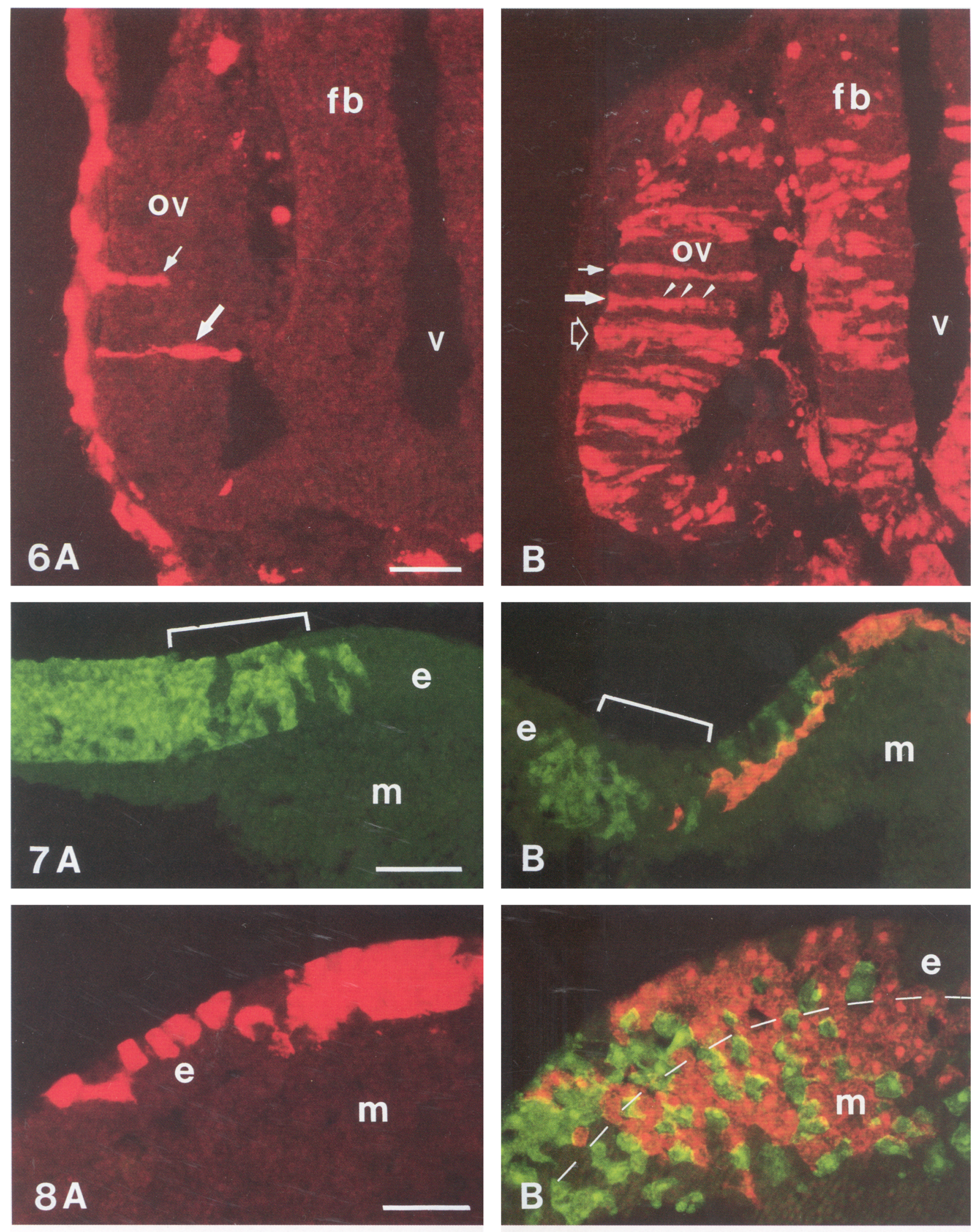


Table 4. Summary of the development of embryos after bilateral D1.1.1 deletion

\begin{tabular}{lllll} 
& & \multicolumn{3}{c}{ Percentage of embryos } \\
\cline { 3 - 5 } & Number & Normal & $\begin{array}{l}\text { Eye } \\
\text { defects }\end{array}$ & $\begin{array}{l}\text { Body } \\
\text { defects }\end{array}$ \\
\hline D1.1.1-deleted & 172 & 59.9 & 19.2 & 20.9 \\
Control & 43 & 86.0 & 4.7 & 9.3
\end{tabular}

The eye defects category includes embryos with no eyes, only one eye, microphthalmia, or histologically distorted eyes. The body defects category includes embryos with an open dorsal axis or embryos that failed to gastrulate. The control group had the vitelline membrane removed only.

D1.1.1 varied a lot from individual to individual (Table 5), confirming that the blastomere progenitors are not restricted to produce fixed numbers of retinal cells.

The descendants of the new blastomere progenitors formed radially oriented columns across all retinal layers and all the subclones contained more than one type of retinal cell (Fig. 9), as described for the normal retina. To determine whether descendants from the new progenitors were distributed in different regions of the retina, the clones were quantified in anterior-toposterior and dorsal-to-ventral retinal thirds. V1.1.1 and V1.2.1 contributed slightly more to anterior than to posterior retina, which was complemented by contralateral V1.2.1 contributing slightly more to posterior retina (Fig. $3 B$ ). V1.1.1 and D1.2.1 contributed slightly more to the dorsal third and V1.2.1 slightly more to the central third of the ipsilateral retina (Fig. $4 B$ ). However, none of these differences were statistically significant. The regional distribution gradient of some blastomeres (e.g., D1.2.1) changed in the D1.1.1-deleted embryos, demonstrating that the spatial distribution of a clone is not yet fixed. As in normal embryos, although there are shallow regional gradients of some of the clones, descendants from all blastomeres could be found in any region of the retina, and no boundaries were seen between clones (Fig. 9).

\section{The changes in retinal lineages of the remaining blastomeres are position dependent}

The regulatory response of the remaining blastomeres to deletion of the D1.1.1 cells differed according to the position of the blastomere in the embryo. Those ventral to the deleted cells

\begin{tabular}{|c|c|c|c|c|}
\hline $\begin{array}{l}\text { Blastomer } \\
(n)\end{array}$ & & Mean \pm SEM & Range & $\%$ Total \\
\hline D1.1.2 (5) & Ipsi & $16 \pm 16$ & $0-84$ & 0.3 \\
\hline & Contra & 0 & 0 & 0 \\
\hline $\mathrm{D} 1.2 .1(6)$ & Ipsi & $1206 \pm 360$ & $322-2632$ & 24.3 \\
\hline & Contra & $96 \pm 96$ & $0-564$ & 1.9 \\
\hline $\mathrm{D} 1.2 .2(6)$ & Ipsi & $94 \pm 62$ & $0-378$ & 1.9 \\
\hline & Contra & 0 & 0 & 0 \\
\hline V1.1.1 (5) & Ipsi & $782 \pm 362$ & $114-1890$ & 15.7 \\
\hline & Contra & $24 \pm 22$ & $0-116$ & 0.5 \\
\hline V1.2.1 (5) & Ipsi & $2144 \pm 548$ & $1062-3722$ & 40.5 \\
\hline & Contra & $732 \pm 314$ & $0-1544$ & 14.7 \\
\hline V1.2.2 (5) & Ipsi & $10 \pm 10$ & $0-50$ & 0.2 \\
\hline & Contra & 0 & 0 & 0 \\
\hline
\end{tabular}

increased their contribution to the retina, while those dorsalvegetal to the deleted cells decreased their contribution (Fig. $1 B$ ). These topographically related lineage changes suggest that the deletion of D1.1.1 may have caused a general dorsal-tovegetal shift in the position of the remaining blastomeres, which in turn caused blastomeres to manifest a retinal fate according to their new positions. To test this possibility, we deleted different animal blastomeres to shift the normal position of the blastomeres in a predictable direction. Three different deletions were done.

Deletion of bilateral V1.1.1 combined with D1.1.1 injection ( $n$ $=14$ ). This operation was designed to see if the dorsally located D1.1.1 shifts its position ventrally to adopt the fate of V1.1.1, which normally does not give rise to retina. After V1.1.1 deletion, half of the embryos developed normal heads and eyes; in these embryos D1.1.1's contribution to retina was quantitatively comparable to that in normal embryos (Fig. 12A). Therefore, D1.1.1 does not take the retinal fate of its ventral neighbor.

Deletion of unilateral D1.1.2 combined with D1.1.1 injection $(n=12)$. This operation was designed to see if D1.1.1 could take a more dorsal-vegetal retinal fate given the opportunity to

\footnotetext{
Figure 6. These photomicrographs show column-like cell clusters in coronal sections of stage 25 optic vesicle (ov). $f b$, forebrain; $v$, ventricle. $A$, Two Texas red-dextran amine-labeled cells (red) derived from ipsilateral V1.2.1 are well separated. One of them (large arrow) spans the entire retina and resembles a progenitor cell in the optic vesicle observed directly after injection (cf. Holt et al., 1988; Wetts and Fraser, 1988). The other cell (small arrow) has been split between two tissue sections. These single cells probably produce the well-separated radial subclones seen in stage 43-44 retina (compare 5, $A$ or $B$ ). B. Ipsilateral D1.1.1 produces many descendants in the stage 25 optic vesicle (ov). Labeled and unlabeled subclones are intermixed, forming an ordered mosaic pattern. The labeled subclones form discrete cell columns, which are composed of only one cell (small solid arrow), a group of radial columnar cells (large solid arrow; the nuclei of individual cells are pointed out with arrowheads), or a group of cells with varying morphologies, including rounded without end feet on a limiting membrane (large open arrow). This micrograph illustrates the different kinds of progenitors available when lineages are initiated at the optic vesicle stage (e.g., Holt et al., 1988; Wetts and Fraser, 1988). Cells at the superior and inferior rims of the retina that appear to have neither vitreal nor pial contacts do not seem to fit the above description due to plane of section artifact. Scale bar, $50 \mu \mathrm{m}$.

Figure 7. Photomicrographs of the prospective retinal area (brackets) of the neural plate (stage 14).e, ectoderm; $m$, mesoderm. Both are parasagittal sections with rostral to the right. $A$, The green cells descended from D1.1.1 are intermixed with unlabeled cells derived from other blastomeres in the prospective retinal area. $B$, The cells derived from D1.1.1 (green cells) and those few derived from V1.2.1 (red cells) are intermixed with unlabeled cells from other blastomeres in the prospective retinal area. Scale bar, $50 \mu \mathrm{m}$.

Figure 8. Photomicrographs of parasagittal sections through the anterior neural area of gastrulae. The right edges of the pictures are the halfway point between the animal and vegetal poles, and the animal pole is to the left. $e$, ectoderm; $m$, mesoderm. $A$, The red cells located at the edge of the D1.1.1 clone are intermixed with many unlabeled cells from other progenitors at stage 11 . The labeled cells are mostly arranged as columnar cells in the outer ectodermal layer $(e)$, resembling the radial columns in the future retina. $B$, At stage 10 the green D1.2.1 descendants already are well mixed with red D1.2.2 descendants in the ectoderm $(e)$ and the underlying mesoderm $(m)$ in the anterior neural area. The border between the ectoderm and mesoderm is indicated by a broken line. Scale bar, $50 \mu \mathrm{m}$.
} 

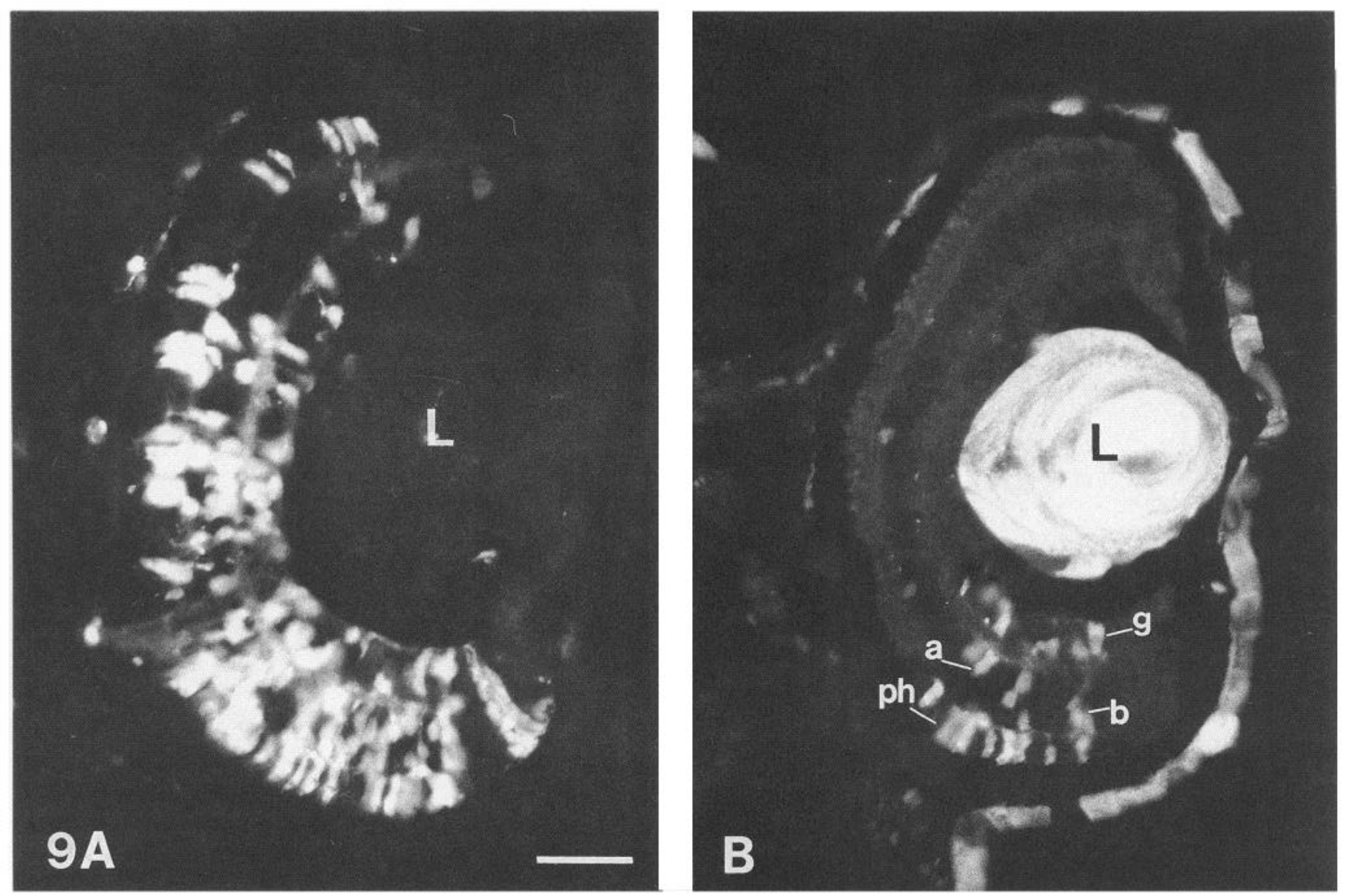

Figure 9. Photomicrographs of stage 43 retinas from D1.1.1-deleted embryos showing that there are normal retinal layers and clonal patterns. $A$, Most of the retina is composed of radial subclones derived from V1.2.1, which in normal embryos contributes very little to the retina. $L$, lens. $B$, Descendants of V1.1.1, which in normal embryos produces no retinal cells, form a radial subclone that spans all retinal layers. Most retinal cell types can be identified in this subclone: $p h$, photoreceptor; $b$, bipolar cell; $a$, amacrine cell; $g$, ganglion cell. Scale bar, $100 \mu \mathrm{m}$.

shift its position in that direction. Ten embryos in this group developed normally; two had smaller eyes. D1.1.1's contribution to retina decreased significantly in the 10 normal-appearing embryos (Fig. 12B). The small retinal contribution of D1.1.1 is quantitatively similar to that of normal D1.1.2 (Fig. 12C). This similarity suggests that after the dorsal-vegetal neighbor is deleted, D1.1.1 shifts toward the vegetal pole and, in turn, adopts the retinal fate of D1.1.2. We have not done the lineage tracing experiments to show which blastomeres compensate for D1.1.1's reduced contribution to retina.

Deletion of unilateral D2.1.2 combined with D1.1.2 injection $(n=15)$. This operation was designed to see if another animal blastomere could adopt a more posterior fate when given the opportunity to shift into the vegetal hemisphere. In this group 13 embryos developed normally; in these cases D1.1.2's contribution to retina was profoundly reduced (Fig. 12D). Sixty percent had no labeled cells in the retina, and the remainder had only a few labeled cells each. This retinal fate is comparable to the normal fate of D2.1.2 to not contribute to retina. In contrast, D1.1.2 does not adopt the fate of its animal neighbor (D1.1.1) when given the opportunity to shift its position in that direction (Figs. 2, 11).

This set of experiments suggests that when cells are removed from the dorsal midline, there is a dorsal-to-vegetal rearrangement in the position of the remaining cells. Second, the remaining cells take on the retinal fate of their new position. However, the positional changes of the blastomeres were not directly visualized; to test directly whether changes in position affect retinal fate, different single-cell transplantations were performed.

Several blastomeres produced retina when placed in the D1.1.1 position. The deletion experiments described above demonstrate that V1.1.1 will produce retina when the D1.1.1 position becomes available. In addition, V1.1.2, which does not contribute to retina in normal embryos or in the D1.1.1-deleted embryos (Fig. $1 B$ ), produced the D1.1.1 pattern of labeled clones in all cases in which it was transplanted to the D1.1.1 position (Table 6). The clones were found in the bilateral ventral forebrain and both retinas, with the majority of the labeled cells in the ipsilateral side (Fig. 13). The number of labeled cells in the retinal clone was comparable to that of normal D1.1.1 (Fig. 14), and the size of the retina in the transplant embryos was the same as in normal embryos ( $p>0.1$; data not shown). A similar result was obtained when V2.1.2, the ventral tier 3 blastomere (Fig. $1 F$ ), was transplanted to the D1.1.1 position (Table 6). Finally, even D1.1.1 must be in its normal dorsal midline position in order to produce retina. In a previous study (Gallagher et al., 1991) we transplanted D1.1.1 to the tier 3 and tier 4 ventral midline; in these cases, although it produced spinal cord and axial mesoderm as is its normal fate, it never produced retina. Likewise, in this study we placed D1.1.1 in the position of V1.1.2 and no labeled cells were found in the retina or forebrain. Thus, all these blastomeres can produce retinal cells when they are located in the correct position (dorsal-animal midline). 


\section{RETINAL VOLUMES IN THE NORMAL AND THE D1.1.1 ABLATED EMBRYOS}

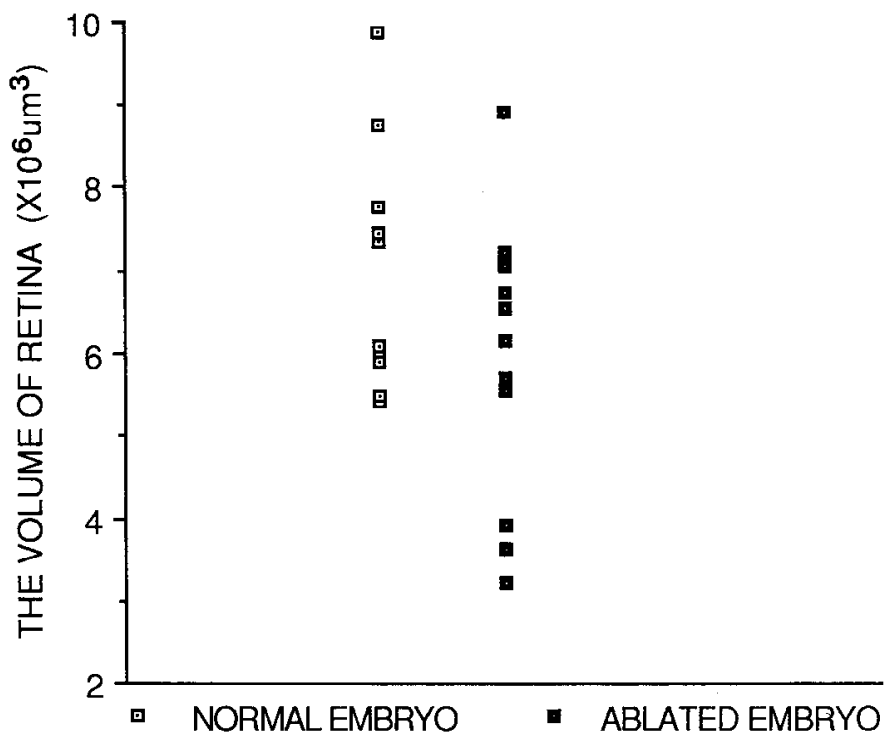

Figure 10. The retinal volume was calculated from area measurements of tissue sections from normal and D1.1.1-deleted embryos that had normal-appearing eyes. In general, the retinal volume was smaller in the operated embryos $(p<0.05)$, although most data points were within the normal range.

Are all blastomeres competent to form retina when located in an appropriate position?

The deletion experiments demonstrate that many animal hemisphere blastomeres that normally do not produce retinal lineages are competent to do so during the regulation that restores the retina. The transplantation experiments described above demonstrate further that even more distant ventral blastomeres are competent to produce retina if they are moved to the appropriate position. However, not all blastomeres are competent; transplantation of dorsal- or ventral-vegetal pole cells (tier 4) into the D1.1.1 position never resulted in labeled clones in the retina (Table 6). Instead, the labeled cells were in the gut, heart, head, and trunk muscle and nephric ducts. About $77 \%$ of these embryos had eyes, and nearly half of these were smaller than normal. The tier 3 dorsal midline blastomere, D2.1.2, had small clones in the retina in only $25 \%$ of the cases. Most members of the clones of the transplanted D2.1.2 were in structures that are not typical of the D1.1.1 position (e.g., ventral somite, nephric ducts, pharynx, and gut; Moody, 1987b). These results indicate that even in the most "retinogenic" position, these vegetal cells could not or had only limited ability to produce a retinal lineage. Therefore, although positional information is important for blastomeres to express a retinal lineage, not all blastomeres are competent to respond to this information.

\section{Discussion}

In several invertebrates it has been possible to observe directly the mitoses leading from zygote to differentiated cells. In general, it has been found that a cell's genealogy can affect the determination of its phenotype in one of three patterns (Kenyon, 1985; Stent, 1985; Davidson, 1990). Cells expressing the same phenotype may (1) descend from a common precursor, (2) share equivalent lineal positions within the mitotic history, or (3) be placed in the appropriate position by their lineage to be induced
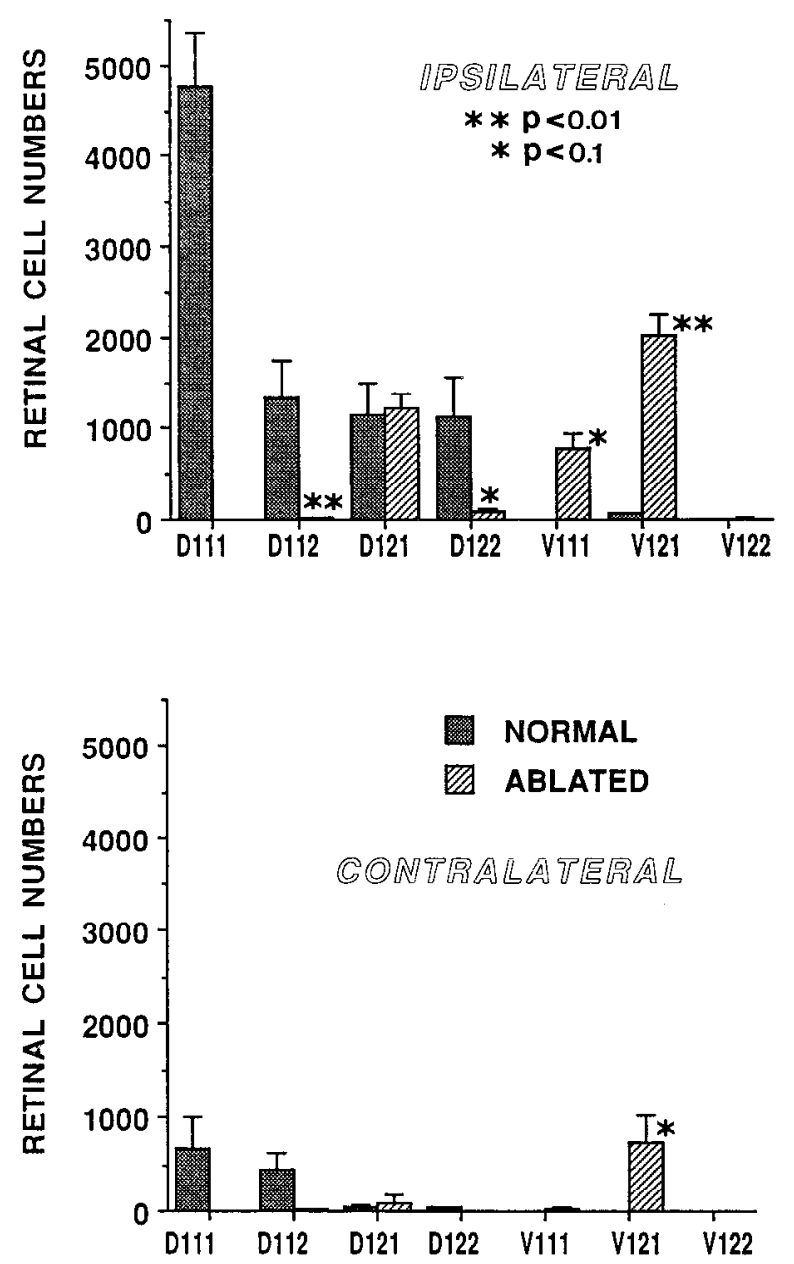

Figure 11. A comparison of blastomere contribution to the retina in normal and D1.1.1-deleted embryos. Ventral blastomeres (V1.1.1 and V1.2.1), which normally produce very few retinal cells, now producc substantial numbers of retinal cells. Two dorsal blastomeres (D1.1.2, D1.2.2) significantly decreased their contributions to retina.

by a spatially confined morphogen. Equivalent studies in vertebrates are difficult to design. However, because a single clutch of frog embryos contains specimens in which the early cleavage blastomeres are nearly identical, it was possible to test whether there are lineage patterns that arc important in the generation of retinal cells, and whether the retinal fates of blastomere progenitors are determined by placing these cells in novel environments.

Table 6. Percentage of embryos with labeled clones in the retina after blastomere transplantation

\begin{tabular}{llrl} 
Donor from: & Host position & $n$ & Clones in retina \\
\hline V1.1.2 & D1.1.1 & 10 & $100 \%$ \\
V2.1.2 & D1.1.1 & 13 & $100 \%$ \\
D1.1.1 & D1.1.1 & 9 & $100 \%$ \\
D1.1.1 & V1.1.2 & 16 & 0 \\
V2.1.1 & D1.1.1 & 9 & 0 \\
D2.1.1 & D1.1.1 & 7 & 0 \\
D2.1.2 & D1.1.1 & 20 & $25 \%$ \\
\hline
\end{tabular}


Figure 12. Comparison of the number of labeled cells in the retina descended from blastomeres in normal embryos and in embryos with various blastomere deletions. The dots in the 32-cell embryo depicted in the upper right corner of each graph illustrate which cell was injected and the hatched areas illustrate which cells were deleted. Numbers of labeled cells in each group were compared by $t$ test.
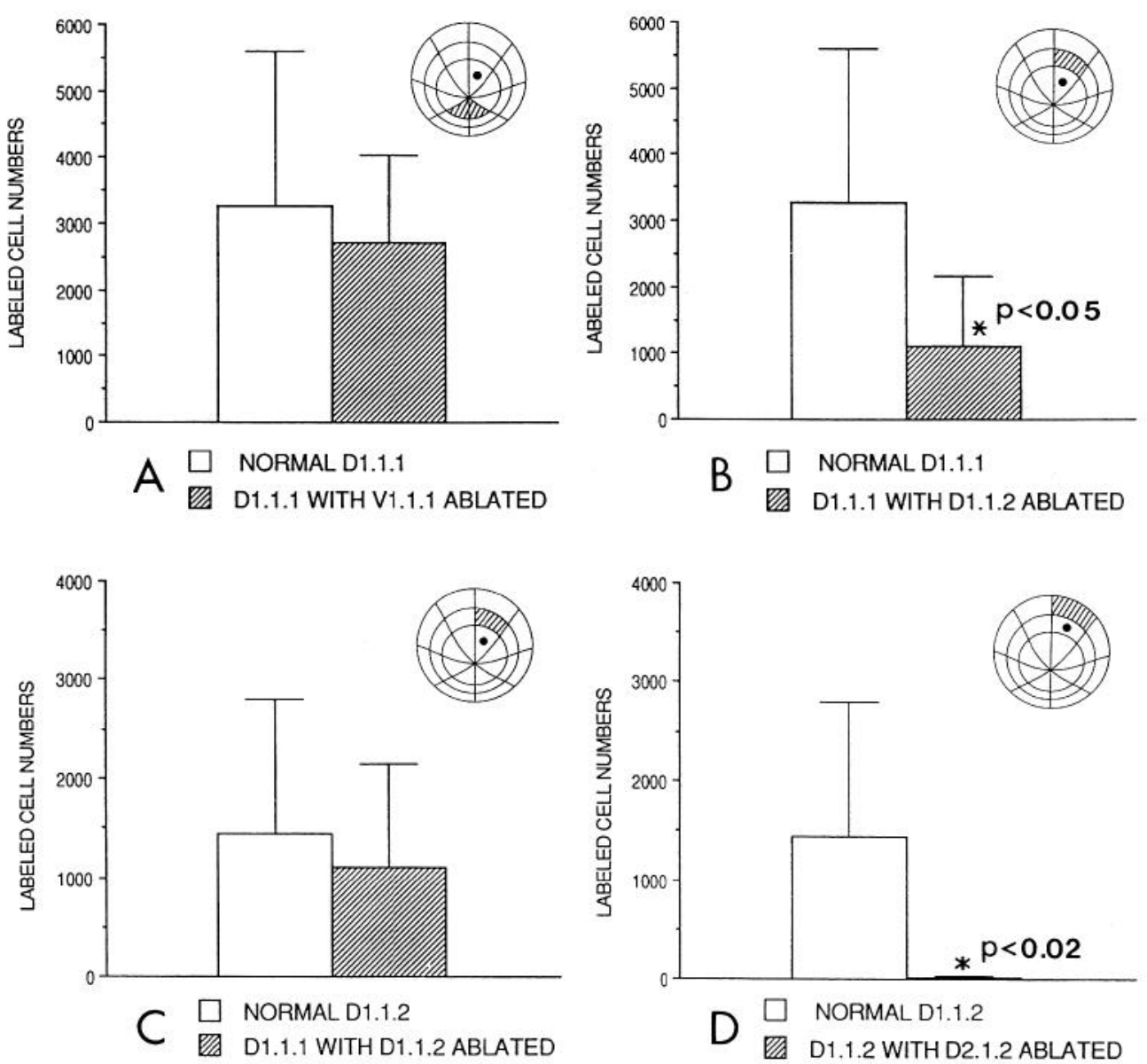

\section{Polyclonal origin of the retina}

It is clear from previous studies that the Xenopus retina is derived from more than one blastomere precursor cell (Jacobson and Hirose, 1981; Dale and Slack, 1987a; Moody, 1987a,b; Moody and Kline, 1990), and it has been proposed that the mouse retina arises from no fewer than 25 founder cells (Williams and Goldowitz, 1992). Although the frog retina descends from multiple early precursors, the specific blastomeres we identified were invariant in the large population $(n=124)$ of embryos studied, and were a restricted subset of those blastomeres destined to produce the forebrain. Our quantitation of a large number of clones demonstrates that the nine blastomeres (five ipsilateral and four contralateral) that produce the retina do not all contribute the same number of cells. Based on population statistics, the most animal dorsal midline cell (D1.1.1) produces about half of the retina, the three other ipsilateral dorsal cells each produce about an eighth of the retina, and the contralateral dorsal cells and ipsilateral ventral cell together produce the remaining eighth of the retina. Thus, the founder cells are unequal contributors to this structure, a finding that contrasts the assumption that founder cells of the chimeric mouse retina each contribute equal numbers of cells (Williams and Goldowitz, 1992). Even though it has been noted previously that part of the retina descends from contralateral blastomeres (e.g., Jacobson and Hirose, 1978), it was surprising that these cells accounted for such a large number of cells.

\section{Are blastomere lineages fixed regarding the number of mitoses?}

In the nematode, genes have been identified that control the number of cell divisions that are characteristic of particular lineages (Chalfie et al., 1981), and it has been hypothesized that similar genes in vertebrates may contribute to the regulation of cell number in CNS populations (Williams and Herrup, 1985). Although previous studies in the retina observed a wide variety of clone sizes, the randomness in progenitor labeling did not allow an analysis of whether the size of a clone of a specific progenitor is invariant. In the frog, however, we had the opportunity to test this hypothesis by determining whether clones descended from the same progenitor in many different animals were the same size. We found that the variation between animals was as much as 10-fold; considering the logarithmic nature of cell divisions, this is a difference of three to four mitoses. The wide range of the blastomeres' contribution to the retina cannot be simply explained as the result of the variation of the cleavage plane in these stereotypic embryos since previous fate mapping showed that interanimal variation is less than $10 \%$ (Moody, $1987 \mathrm{a}, \mathrm{b})$. These results indicate that blastomere progenitors are not determined to produce a fixed number of progeny in the retina. Quantitation of clone sizes in another forebrain structure in the frog, the hypothalamic dopamine nucleus, also found 10 fold differences in cell numbers among clones derived from the same precursor (Huang and Moody, 1992). Therefore, if there 

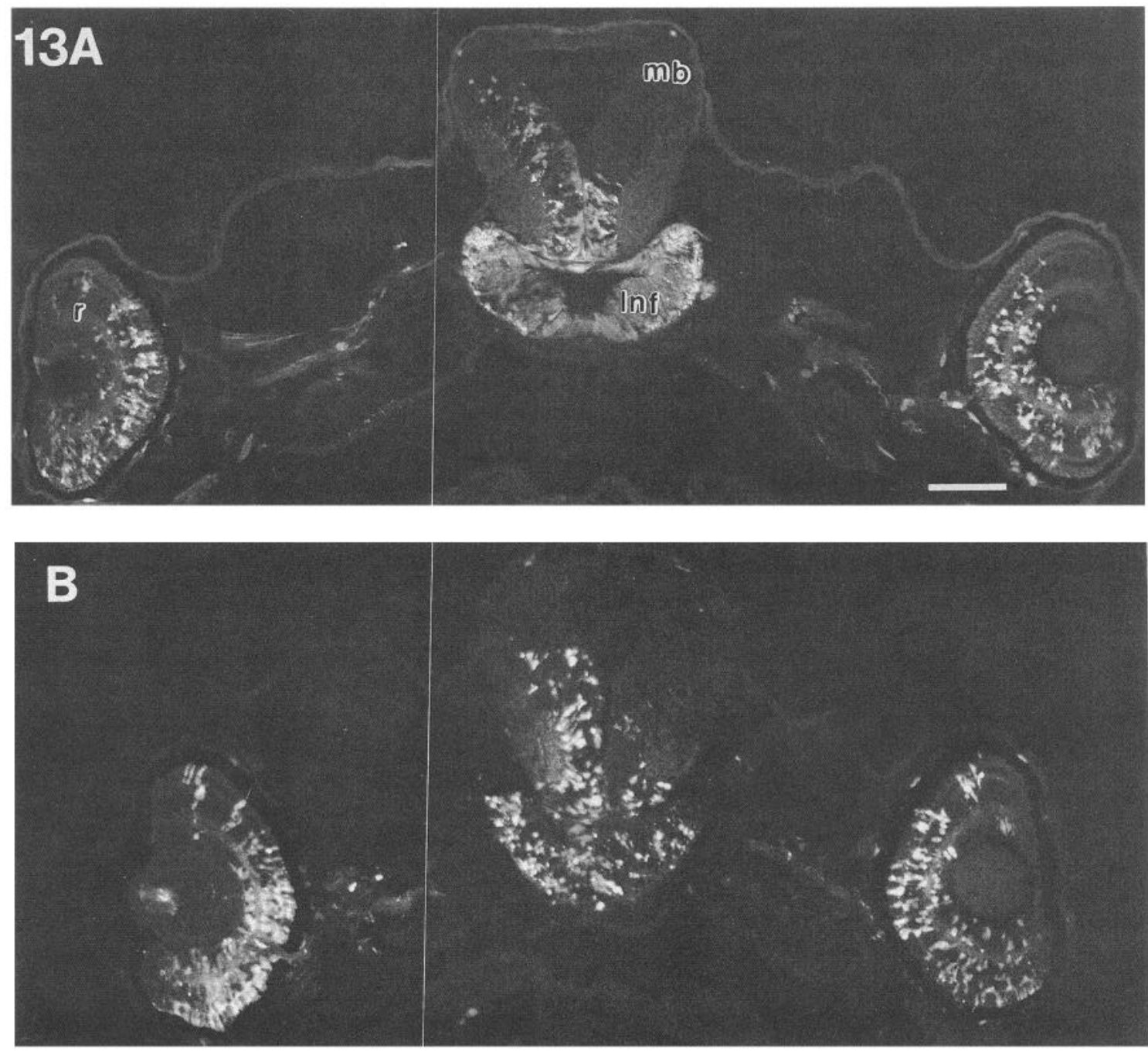

Figure 13. Photomicrographs show that the distribution of the labeled descendants of V1.1.2 (A), which was transplanted to the position of D1.1.1, is indistinguishable from the pattern of descendants from a normal D1.1.1 (B). mb, midbrain; Inf, infundibulum; $r$, retina (ipsilateral to injection). Scale bar, $200 \mu \mathrm{m}$.

is any lineage control of the number of mitoses, it must be exerted much later than cleavage stages.

\section{Are blastomere lineages fixed regarding spatial distribution?}

Previous fate maps have noted a spatial arrangement in the retina whereby dorsal blastomeres give rise mostly to ventral retina and ventral blastomeres give rise mostly to dorsal retina (Jacobson and Hirose, 1978, 1981; Dale and Slack, 1987a; Moody, 1987a,b). In fact, Jacobson $(1983,1985)$ proposed that clones initiated later in the blastula respect boundaries, much like insect imaginal disk compartment boundaries. Such clonal segregation would have an interesting correlation with the later spatial restriction of GC axons as they innervate distinctly different regions of the optic tectum. However, with precise quantitation of the number of cells in each clone in the different retinal sectors, we found no evidence for boundaries that segregate clones from different cleavage stage progenitors. There are shallow gradients in the density of some blastomere clones in either the anterior-posterior (nasal-temporal) or dorsal-ventral directions, but no strict boundaries; the descendants from each blastomere can be found in any region of the retina. Thus,

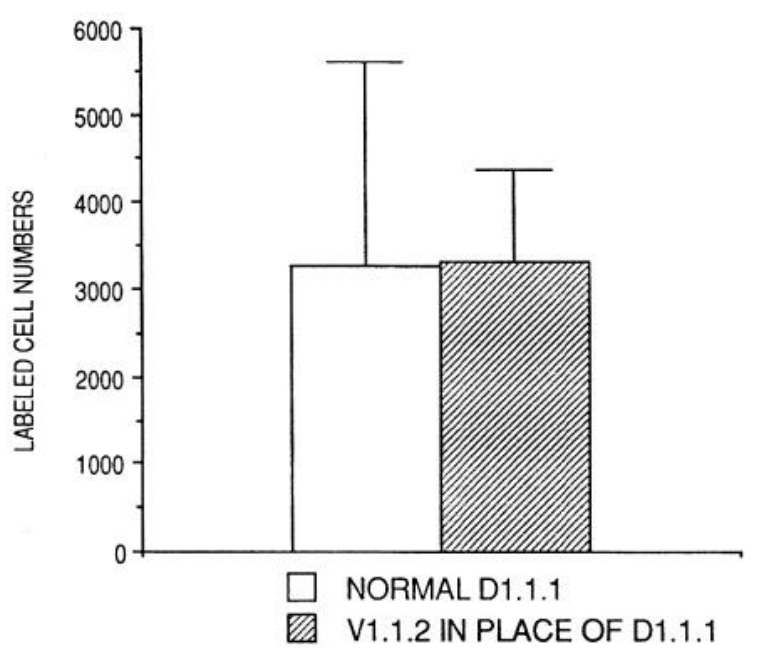

Figure 14. The number of labeled retinal cells that descended from V1.1.2, which was transplanted to the site of D1.1.1, is the same as the number that descended from normal D1.1.1. 
the retina is a true mosaic of the clones of several blastomere progenitors. In contrast, clones that are initiated closer to the terminal mitosis, for example, in the retina (Holt et al., 1988; Wetts and Fraser, 1988), chick spinal cord (Leber et al., 1990), chick hindbrain (Fraser et al., 1990), or chick optic tectum (Gray et al., 1988), do show some spatial restriction.

\section{Are blastomere lineages fixed regarding cell phenotype?}

In every animal studied, the clones contained all retinal cell types, indicating that blastomere origin does not dictate a single phenotype, and all blastomeres are able to produce multiple cell types. This finding is not surprising since previous lineage studies in both the rodent and frog retina demonstrated that retinal precursor cells can produce multiple cell types even at their final cell division (Holt et al., 1988; Wetts and Fraser, 1988; Turner et al., 1990). Interestingly, the descendants from the different blastomeres are distributed in the three retinal layers in the same proportion as the laminar distribution of cells in the whole retina (Table 2). However, by the time radial subclones are established, many have a laminar distribution that is different from that of the whole retina, suggesting that a laminar preference is established sometime during the formation of the radial subclones, and that laminar preference is established prior to phenotype determination. A similar conclusion has been reached for mammalian cortical development (McConnell, 1991).

\section{Formation of the columnar clone pattern}

The progeny of a blastomere are not uniformly distributed throughout the retina, but form small, separated cell clusters, which are coherent in the radial axis. In terms of distribution pattern and cell composition these clusters are very similar to those observed from labeling retinal progenitors at late development in Xenopus (Holt et al., 1988; Wetts and Fraser, 1988), rat (Price et al., 1987; Turner and Cepko, 1987), and mouse (Turner et al., 1990). This fact suggests that at the time when these later studies marked cells, the optic vesicle is a mosaic of neuroepithelial cells derived from the different blastomere progenitors. In fact, this is the case: in the optic vesicle, blastomere clones already are dispersed throughout all regions of the retina and column-like cell clusters already are formed (Fig. 6). This observation raises two questions: can our observations of blastomere subclones in the optic vesicle explain the diversity of clones generated by marking cells at late stages, and how does this mosaic retinal neuroepithelium arise?

When clones are initiated from optic vesicle stages, they vary a lot in size (Holt et al., 1988; Wetts and Fraser, 1988). The progenitor cells that were injected in these studies must have been members of one of three types of radial subclones: single columnar cells, clusters of a few of these cells, or larger clusters containing rounded cells that no longer are attached to the limiting membranes (Fig. 6). Since retinal cells begin to leave the cell cycle at stages 24-25 (Holt et al., 1988), the rounded cells probably are postmitotic or in their final cell division, while the columnar cells probably will go through several more rounds of division. Thus, if a rounded cell were labeled, its clone probably would consist of one or two cells, whereas if a columnar cell were labeled, its clone probably would consist of several descendants. Furthermore, small groups of columnar cells may be a clonally related cluster that has already gone through one or two mitoses; if one of these cells were labeled, its clone would be intermediate in size. Thus, the Xenopus optic vesicle appears to be a temporal mosaic regarding the number of mitoses re- maining in the different sublineages. The size variations in late initiated clones (Holt et al., 1988; Wetts and Fraser, 1988) probably arise because different injected cells were in different parts of their mitotic program. This temporal mosaicism would prevent single cell injections from revealing a lineage module like that proposed in the mouse retina (Williams and Goldowitz, 1992). Our data also do not reveal a lineage module that consists of the same number of cells. The radial clusters varicd in size because either the founding neuroepithelial cells divide different numbers of times, or the clusters descend from more than one founder.

We do not know when the temporal mosaic is initiated during retinal development, but the clonal mosaic of the optic vesicle has its beginnings at least as early as the beginning of gastrulation, as evidenced by the intermixed blastomere clones in the anterior neural area of the gastrula and in the prospective retinal area of the neural plate (Figs. 7, 8). Although the lack of sharp boundaries between radial subclones in the stage $43-44$ retina may result from a slow, progressive cell mixing (Wetts and Fraser, 1989), the cell clusters in the optic vesicle are too coherent and are distributed too far apart in the different quadrants of the retina (Fig. 6) for slow mixing to account for the lineage mosaic. Furthermore, the mosaic pattern observed at the beginning of cyc formation is as mixed as that in the tadpole retina, suggesting that mixing ceases to a large extent at the optic vesicle stage. The mosaic pattern in the retina most likely results from extensive cell mixing during gastrulation and neurulation, which disperses the descendants of the blastomere progenitors into all regions of the presumptive retinal area; a later restriction of cell movement and mixing of the descendants of retinal neuroepithelial cells results in the formation of columnar subclones. This pattern of early lateral mixing of cells and later restricted movement in the radial dimension is very similar to that reported in the chick optic tectum (Gray et al., 1988; Gray and Sanes, 1991).

\section{Is the major progenitor necessary for normal retina development?}

Although the retina is polyclonal in origin, more than half of the retina descends from the two D1.1.1 cells. One classical test of whether cmbryonic lincages are irreversibly committed at a particular developmental time is to delete the normal progenitor and observe whether the tissue is restored by the remaining cells (Davidson, 1990). For example, in tunicates if the two muscleproducing blastomeres are removed from the eight-cell embryo, a muscleless larva develops (Whittaker et al., 1977). In contrast, there are many studies that show that frog embryos regulate; for example, removal of any of the eight-cell blastomeres results in a normal appearing embryo as long as one dorsal and one ventral-vegetal blastomere remains (Kageura and Yamada, 1984). The present study demonstrates that when the two major retinal progenitors are deleted, the remaining cells often, but not always, reconstitute a normal-sized retina (Fig. 10). Thus, in the majority of cases, the D1.1.1 progenitor is not required for retinal development. This result is consistent with previous findings that spinal Rohon-Beard neurons (Jacobson, 1981a,b) and hypothalamic dopamincrgic ncurons (Huang and Moody, 1992) can be, but are not always, numerically restored after deletion of their major cleavage stage progenitor. We cannot ignore the fact that in many embryos the retinas were smaller than normal. Some cases did not achieve full restoration because of nonspecific damage (Table 1), but in others some aspect of retinal fate was perturbed. 


\section{Is D1.1.I committed to a retinal fate?}

We were surprised that the D1.1.1-defective embryos had apparently normal eyes in the majority of cases because it has been shown that the mother blastomere (D1.1) is determined regarding its dorsal axial fatc. If grown in culture or transplanted to the ventral-vegetal pole, D1.1 differentiates into dorsal mesoderm (notochord) and frequently CNS (Gallagher et al., 1991). In fact, RNA from this cell can induce ectopic dorsal axes when injected into ventral-vegetal cells (Hainski and Moody, 1992). Interesting, however, is the fact that when D1.1 or its 32-cell daughters (Gallagher et al., 1991; present study) are transplanted to a ventral position, retinal cells are not among the progeny. Therefore, the early commitment of this blastomere begins with regional (dorsal) rather than phenotype (retinal) specification, as has been observed in numerous marine organisms and vertebrates (Davidson, 1990) and in vertebrate CNS (Kimmel and Warga, 1986; McConnell, 1991).

\section{Are all blastomeres competent to express a retinal fate?}

Deletion studies cannot address the state of commitment of the delcted cell, but they can test whether a particular fate is restricted to a subset of cells. Normal fate mapping demonstrates that the retina descends from five of eight animal hemisphere blastomeres per side of the 32-cell embryo, but these are not the only cells capable of producing retinal cells. Two ventral blastomeres (V1.1.1, V1.2.2) can become retinal progenitors when D1.1.1 is deleted, and another (V1.1.2) can do so when transplanted to the D1.1.1 site. Thus, all animal hemisphere blastomeres are competent to produce retinal lineages.

In contrast, not all vegetal hemisphere blastomeres are competent to produce retinal lineages. Transplanted V2.1.2 produces retina in all cases, whereas its dorsal counterpart (D2.1.2) does so only $25 \%$ of the time. Neither the dorsal nor the ventral midline vegetal pole cell (D2.1.1, V2.1.1), which normally mostly populates endoderm (Moody, 1987b), produces retina when transplanted to the site of the embryo that normally has the grcatest retina-producing potcntial. These differences in the competence of animal versus vegetal cells to produce retina may be related to the observations that animal pole cells remain pluripotent through late blastula stages (Snape et al., 1987), whereas vegetal pole cells become restricted earlier (Heasman et al., 1984). The molecular basis of this fate restriction is not known, but it involves the suppression of vegetal cells from responding to neural induction.

\section{Blastomere position is an important determinant of retinal fate}

One interesting observation from this study is that the response of the remaining blastomeres to the deletion of D1.1.1 is not universally a compensating one; ventral blastomeres increase but dorsal ones decrease their production of retinal cells. Why do different blastomeres respond differently to this deletion? It has long been postulated that the position of cells within a morphogenetic field determines that cell's identity, with respect to its future fate (Wolpert, 1971). We attempted to test whether changes in position correlated with changes in retinal fate by deleting cells on the animal and vegetal side of the two dorsal midline retinal progenitors (D1.1.1 and D1.1.2). In both cases when the more dorsal-vegetal neighbor was removed, the retinal fate taken was different from its normal fate and indistinguishable from that of the deleted neighbor. The same was not true when the more ventral-animal neighbor was removed. These results suggest that deletions in the dorsal-animal region of the embryo result in unidirectional position shifts (ventral to dorsal, animal to vegetal) that directly affect retinal fate. This explanation is consistent with the results that after D1.1.1 deletion, the remaining dorsal blastomeres decrease production of retina whereas the ventral blastomeres increase production to become the major progenitors (Fig. $1 B$ ). Furthermore, this movement is consistent with the direction that the dorsal midline clones take during epiboly and gastrulation (Moody, 1985; Hainski and Moody, 1992). Since the capacity of mesoderm to induce neural structures and the competence of the responding ectoderm is gradually regionalized during late gastrulation and neurulation, and the retina-inducing capacity of mesoderm is restricted to the middle part of the mesoderm (Saha and Grainger, 1992), it is reasonable that in normal embryos this mesoderm is overlain mainly by the ectodermal descendants of D1.1.1, and after deletion of D1.1.1 is overlain by the ectodermal descendants of ventral blastomeres (mainly V1.2.1 and V1.1.1).

That position determines retinal fate is proven by the fact that any animal blastomere makes retina when placed in the D1.1.1 position. It is not known what cellular interactions contribute to "position" in the Xenopus embryo, although several types of interactions are regionalized. For example, certain proteins are synthesized (Klein and King, 1988) or are already present (Miyata et al., 1987) on the dorsal side of the cleavage stage embryo. There is a mesoderm-inducing signal specific to the dorsal side (Dale and Slack, 1987b) and gap junctional communication is more prevalent on the dorsal than ventral side (Guthrie, 1984). Any of these factors might provide the environment in the dorsal-animal quadrant of the embryo that ultimately leads to the determination of retinal lineages.

Nonetheless, position is not the only determinant of retinal fate. Vegetal pole cells transplanted into the correct position cannot produce retinal cells. It has been shown by placing vegetal pole cells into the blastocoele at different stages that the cells we transplanted are still multipotent (Heasman et al., 1984). Thus, their lack of competence to form retinal lineages is not due to a restriction to an endodermal fate, but probably is due to a lack of receptor or transduction molecule that renders their descendants incapable of responding to whatever signal instructs cells in the D1.1.1 position to make retina (see Jessell and Melton, 1992). Understanding the signaling and receptor molecules involved in the induction of retinal lineages is an important next avenue of investigation.

\section{References}

Brun RB (1981) The movement of the prospective eye vesicles from the neural plate into the neural fold in Ambystoma and Xenopus laevis. Dev Biol 88:192-199.

Chalfie M, Horvitz HR, Sulston JE (1981) Mutations that lead to reiterations in the cell lineages of $C$. elegans. Cell 24:59-69.

Dale L, Slack JMW (1987a) Fate map for the 32-cell stage of Xenopus laevis. Development 99:527-551.

Dale L, Slack JMW (1987b) Regional specification within the meso derm of early embryos of Xenopus laevis. Development 100:279-295.

Davidson EH (1990) How embryos work: a comparative view of diverse modes of cell fate specification. Development 108:365-389.

Eagleson GW, Harris WA (1990) Mapping of the presumptive brain regions in the neural plate of Xenopus laevis. J Neurobiol 21:427440.

Fraser S, Keynes R, Lumsden A (1990) Segmentation in the chick embryo hindbrain is defined by cell lineage restrictions. Nature 344: $431-435$.

Gallagher BC, Hainski AM, Moody SA (1991) Autonomous differ- 
entiation of dorsal axial structures from an animal cap cleavage stage blastomere in Xenopus. Development 112:1103-1114.

Gray GE, Sanes JR (1991) Migratory paths and phenotypic choices of clonally related cells in the avian optic tectum. Neuron 6:211-225.

Gray GE, Glover JC, Majors J, Sanes JR (1988) Radial arrangement of clonally related cells in the chicken optic tectum: lineage analysis with a recombinant retrovirus. Proc Natl Acad Sci USA 85:73567360.

Guthrie SG (1984) Patterns of junctional communication in the early amphibian embryo. Nature 31 1:149-151.

Hainski AM, Moody SA (1992) Xenopus maternal RNAs from a dorsal animal blastomere induce a secondary axis in host embryos. Development 116:347-355.

Heasman J, Wylie CC, Hausen P, Smith JC (1984) Fates and states of determination of single vegetal pole blastomeres of Xenopus laevis. Cell 37:185-194.

Herrup K (1986) Cell lineage relationships in the development of the mammalian CNS: role of cell lineage in control of cerebellar Purkinje cell number. Dev Biol 115:148-154.

Holt CE, Bertsch TW, Ellis HM, Harris WA (1988) Cellular determination in the Xenopus retina is independent of lineage and birthdate. Neuron 1:15-26.

Huang S, Moody SA (1992) Does lineage determine the dopamine phenotype in the tadpole hypothalamus? A quantitative analysis. $\mathrm{J}$ Neurosci 12:1351-1362.

Jacobson M (1981a) Rohon-Beard neuron origin from blastomeres of the 16-cell frog embryo. J Neurosci 1:918-922.

Jacobson M (1981b) Rohon-Beard neurons arise from a substitute ancestral cell after removal of the cell from which they normally arise in the 16-cell frog embryo. J Neurosci 1:923-927.

Jacobson M (1983) Clonal organization of the central nervous system of the frog. III. Clones stemming from individual blastomeres of the 128-, 256-, and 512-cell stages. Dev Biol 71:191-202.

Jacobson M (1985) Clonal analysis and cell lineage of the vertebrate central nervous system. Annu Rev Neurosci 8:71-102.

Jacobson M (1991) Developmental neurobiology, 3d ed. New York: Plenum.

Jacobson M, Hirose G (1978) Origin of the retina from both sides of the embryonic brain: a contribution to the problem of crossing at the optic chiasma. Science 202:637-639.

Jacobson M, Hirose G (1981) Clonal organization of the central nervous system of the frog. II. Clones stemming from individual blastomeres of the 32- and 64-cell stages. J Neurosci 1:271-284.

Jessell TM, Melton DA (1992) Diffusible factors in vertebrate embryonic induction. Cell 68:257-270.

Kageura H, Yamada K (1984) Pattern regulation in defect embryos of Xenopus laevis. Dev Biol 101:410-415.

Keller RE (1975) Vital dye mapping of the gastrula and neurula of Xenopus laevis. I. Prospective area and morphogenetic movements of the superficial layer. Dev Biol 42:222-241.

Kenyon C (1985) Cell lineage and the control of Caenorhabditis elegans development. Philos Trans R Soc Lond [Biol] 312:21-38.

Kimmel CB, Warga RM (1986) Tissue-specific cell lineages originate in the gastrula of the zebrafish. Science 231:365-368.

Klein SL (1987) The first cleavage furrow demarcates the dorsal-ventral axis in Xenopus embryos. Dev Biol 120:299-304.

Klein SL, King ML (1988) Correlations between cell fate and the distribution of proteins that are synthesized before the midblastula transition in Xenopus. Rouxs Arch Dev Biol 197:275-281.

Leber SM, Breedlove SM, Sanes JR (1990) Lineage, arrangement, and death of clonally related motoneurons in chick spinal cord. J Neurosci 10:2451-2462.

McConnell SK (1991) The generation of neuronal diversity in the central nervous system. Annu Rev Neurosci 14:269-300.

Miyata S, Kageura H, Kihara HK (1987) Regional differences of pro- teins in isolated cells of early embryos of Xenopus laevis. Cell Differ 21:47-52.

Moody SA (1985) Gastrulation movements of progeny derived from 16-cell stage Xenopus blastomeres. J Cell Biochem 9B:275.

Moody SA (1987a) Fates of the blastomeres of the 16-cell stage Xenopus embryo. Dev Biol 119:560-578.

Moody SA (1987b) Fates of the blastomeres of the 32-cell stage Xenopus embryo. Dev Biol 122:300-319.

Moody SA (1989) Quantitative lineage analysis of the origin of frog primary motor and sensory neurons from cleavage stage blastomeres. J Neurosci 9:2919-2930.

Moody SA, Kline MJ (1990) Segregation of fate during cleavage of frog (Xenopus laevis) blastomeres. Anat Embryol (Berl) 182:347-362.

Nakamura O, Takasaki H, Nagata A (1978) Further studies of the prospective fates of blastomeres at the 32-cell stage of Xenopus laevis embryos. Med Biol 56:355-360.

Nieuwkoop PD, Faber J (1964) Normal table of Xenopus laevis (Daudin), 2d ed. Amsterdam: Elsevier-North Holland.

Price J, Turner D, Cepko C (1987) Lineage analysis in the vertebrate nervous system by retrovirus-mediated gene transfer. Proc Natl Acad Sci USA 84:154-160.

Roux W (1888) Beitrage zur Entwicklungsmechnik des embryo. Virchows Arch Pathol Anat Physiol Klin Med 114:113-153. Reprinted in: Foundations of experimental embryology (Willer BH, Oppenheimer JM, eds; Laufer H, trans), pp 2-37. New York: Hafner, 1974.

Saha MS, Grainger RM (1992) A labile period in the determination of the anterior posterior axis during early neural development. Neuron 8:1003-1014.

Snape A, Wylie CC, Smith JC, Heasman J (1987) Changes in states of commitment of single animal polc blastomeres of Xenopus laevis. Dev Biol 119:503-510.

Stent G (1985) The role of cell lineage in development. Philos Trans R Soc Lond [Biol] 312:3-19.

Sternberg PW, Horvitz HR (1989) The combination of two intercellular signaling pathways specifies three position-dependent cell fates in C. elegans. Cell 58:679-693.

Sulston JE, Schierenberg E, White JG, Thomson JN (1983) The embryonic cell lineage of the nematode Caenorhabditis elegans. Dev Biol 100:64-119.

Turner DL, Cepko CL (1987) A common progenitor of neurons and glia persists in rat retina late in development. Nature 328:131-136.

Turner DL, Snyder EY, Cepko CL (1990) Lineage-independent determination of cell type in the embryonic mouse retina. Neuron $4: 833$ 845.

Wetts R, Fraser SE (1988) Multipotent precursors can give rise to all major cell types of the frog retina. Science 239:1142-1145.

Wetts R, Fraser SE (1989) Slow intermixing of cells during Xenopus embryogenesis contributes to consistence of the blastomere fate map. Development 105:9-15.

Wetts R, Serbedzija GN, Fraser SE (1989) Cell lineage analysis reveals multipotent precursors in the ciliary margin of the frog retina. Dev Biol 136:254-263.

White JG, Horvitz HR, Sulston JE (1982) Neuron differentiation in cell lineage mutants of Caenorhabditis elegans. Nature 297:584-589.

Whittaker JR, Ortolani G, Farinella-Ferruzza N (1977) Autonomy of acetylcholinesterase differentiation in muscle lineage cells in ascidian embryos. Dev Biol 55:196-200.

Williams RW, Goldowitz D (1992) The structure of clonal and polyclonal cell arrays in chimeric mouse retina. Proc Natl Acad Sci USA 89:1184-1188.

Williams RW, Herrup K (1985) The control of neuron number. Annu Rev Neurosci 11:423-453.

Wolpert L (1971) Positional information and pattern formation. Curr Top Dev Biol 6:183-224. 